\title{
Topographic Organization of Corticospinal Projections from the Frontal Lobe: Motor Areas on the Lateral Surface of the Hemisphere
}

\author{
San-Qiang He, Richard P. Dum, and Peter L. Strick \\ Research Service, Veterans Affairs Medical Center, and Departments of Neurosurgery and Physiology, SUNY Health \\ Science Center at Syracuse, Syracuse, New York 13210
}

We examined the topographic organization of corticospinal neurons in the primary motor cortex and in the two premotor areas on the lateral surface of the hemisphere [i.e., the dorsal premotor area (PMd) and the ventral premotor area (PMv)]. In two macaques, we labeled corticospinal neurons that project beyond $\mathrm{T7}$ or $\mathbf{S 2}$ by placing crystals of HRP into the dorsolateral funiculus at these segmental levels. In another seven macaques, we labeled corticospinal neurons that project to specific segmental levels of the spinal cord by injecting the fluorescent tracers fast blue and diamidino yellow into the gray matter of the cervical and lumbosacral segments. In one set of experiments $(n=2)$, we defined the representations of the arm and leg in each cortical motor area by injecting one of the two fluorescent tracers into lower cervical segments (C7-T1) and the other fluorescent tracer into lower lumbosacral segments (L6-S1) of the same animal. In another set of experiments $(n=5)$, we defined the representations of distal and proximal parts of the forelimb in each cortical motor area by injecting one of the two fluorescent tracers into lower cervical segments (C7-T1) and the other tracer into upper cervical segments (C2-C4) of the same animal.

In the primary motor cortex and the PMd, cortical regions that project to lower cervical segments were largely separate from those that project to lower lumbosacral segments. In the PMv, few neurons were labeled after tracer injections into lower cervical segments or lower lumbosacral segments. However, corticospinal neurons were labeled in the PMv after tracer injections into upper cervical segments and after HRP placement in the dorsolateral funiculus at T7. The region of the PMv that projects to upper cervical segments was separate from that which projects below T7.

Cortical regions that project to upper and lower cervical segments of the spinal cord overlapped considerably in the primary motor cortex and in the PMd. Despite this overlap, we found that the regions of the primary motor cortex and

\footnotetext{
June 3, 1992; revised Sept. 2, 1992; accepted Sept. 9, 1992.

This work was supported by funds from the Veterans Affairs Medical Research Service and Rehabilitation Research and Development Service, and by U.S. Public Health Service Grants 02957 and 24328. We thank Mr. Mike Page for development of computer programs, Ms. Mary Lou Cherney and Sarah Fitzpatrick for their expert technical assistance, and Dr. Kenneth D. Hutchins for his assistance in some of the initial experiments. This material has been presented by S.-Q.H. in partial fulfillment of the requirements for a Doctor of Philosophy degree in Physiology from SUNY-HSC at Syracuse.

Correspondence should be addressed to Dr. Peter L. Strick, Research Service (151), V.A. Medical Center, Syracuse, NY 13210.

Copyright (C) 1993 Society for Neuroscience $0270-6474 / 93 / 130952-29 \$ 05.00 / 0$
}

PMd that project most densely to upper cervical segments were largely separate from those that project most densely to lower cervical segments. Furthermore, we found two separate regions within area 4 that send corticospinal projections primarily to the lower cervical segments. One of these regions was located within the classical "hand" area of the primary motor cortex. The other was located at the medial edge of arm representation in the primary motor cortex.

These results provide new insights into the pattern of body representation in the primary motor cortex, PMd, and PMv. Our findings support the classic distinction between the "arm" and "leg" representation in the primary motor cortex. However, the demonstration that two regions in the primary motor cortex project densely to lower cervical segments suggests that the organization of distal representation in the "arm" area is more complex than previously thought. Our study provides additional support for the existence of separate arm and leg representations in the PMd and possibly in the PMv. Furthermore, we present evidence that the arm area of the PMd contains separate regions of distal and proximal representation. Thus, our results imply that the PMd is involved in the control of both distal and proximal arm movements. Finally, we found some striking differences in the pattern of corticospinal projections from the PMd and PMv. These differences provide additional support for distinguishing between these two premotor areas.

[Key words: premotor areas, primary motor cortex, motor cortex, arm areas, motor control, arm movement]

This is the first in a series of reports of the results of studies on the topographic organization of the corticospinal system. In this article, we will describe our findings on the origin of corticospinal projections from three motor areas on the lateral convexity of the hemisphere: the primary motor cortex, the dorsal premotor area (PMd), which is in and adjacent to the superior precentral sulcus (SPcS), and the ventral premotor area (PMv), which is in and adjacent to the caudal bank of the arcuate sulcus (ArS) at its inferior limb. In subsequent reports, we will present our findings on the origin of corticospinal projections from (1) the premotor areas on the medial wall of the hemisphere and (2) somatosensory and posterior parietal cortical areas.

It is now morc than 40 ycars since the publication of the classic study by Woolsey and his colleagues on the precentral motor area of macaques (Woolsey et al., 1952). This study continues to influence our concepts about not only the primary motor cortex, but also the function and even the existence of a premotor cortex. The central finding of this classic study was 
that the precentral motor field contained a complete map of the body. A large part of the body map was locatcd in cytoarchitectonic area 4 . However, the representation of axial body musculature was located in the caudal part of area 6 . In fact, it was principally the presence of axial representation in caudal area 6 and the lack of skeletomotor effects following stimulation in the rostral part of area 6 that led the authors to conclude that their findings were "incompatible with the idea of a premotor area" (Woolsey et al., 1952, p 259).

There is now considerable evidence to support the existence of multiple premotor areas in the frontal lobe (e.g., Matsumura and Kubota, 1979; Muakkassa and Strick, 1979; Rizzolatti et al., 1981a,b, 1988; Weinrich and Wise, 1982; Godschalk et al., 1984, 1985; Schell and Strick, 1984; Weinrich et al., 1984; Wise and Mauritz, 1985; Kurata and Tanji, 1986; Matelli et al., 1986; Martino and Strick, 1987; Gentilucci et al., 1988; Hutchins et al., 1988; Kurata, 1989, 1991; Dum and Strick, 1991a,b; Luppino et al., 1991). However, the results of Woolsey et al. (1952) have led to the persistent notion that the premotor areas in the caudal part of area 6 (i.e., the PMd and PMv) are largely concerned with the control of proximal and axial body musculature (Humphrey, 1979; Freund and Hummelsheim, 1985). Thus, one of the goals of the present study was to use anatomical techniques to explore the basis of this concept. In general, there has been some uncertainty about the presence and location of body maps in the PMd and PMv (e.g., Muakkassa and Strick, 1979; Godschalk et al., 1984; Strick, 1985; Kurata and Tanji, 1986; Gentilucci et al., 1988; Rizzolatti et al., 1988; Kurata, 1989). Thus, a second overall goal of this study was to use anatomical techniques to define the pattern of fore- and hindlimb representation in the PMd and PMv.

To "map" the fore- and hindlimb representations in the premotor areas, we injected one fluorescent tracer into lower cervical segments (C7-T1) and then injected a second fluorescent tracer into lower lumbosacral segments (L6-S1) of the same animal. In another set of experiments designed to map the representations of the proximal and distal forelimb, we injected one fluorescent tracer into upper cervical segments (C2-C4) and then injected a second fluorescent tracer into lower cervical segments (C7-T1) of the same animal. In each set of experiments, we reconstructed the distribution of the corticospinal neurons that were labeled by retrograde transport of the two tracers.

Our results add further support to the hypothesis that the premotor areas function, in part, at the same hierarchical level as the primary motor cortex (Strick, 1988; Dum and Strick, 1991a). We found that the PMd projects to upper cervical, lower cervical, and lower lumbosacral segments. Our results support the view that the PMd, like the primary motor cortex, contains separate representations of the arm and leg. In addition, our findings provide evidence that the PMd contains a substantial distal representation of the forelimb, as well as a proximal representation. We confirmed our prior observation that the PMv has a corticospinal projection that is largely focused on upper cervical segments (Martino and Strick, 1987; Dum and Strick, $1989,1991 \mathrm{~b})$. The results of tracer injections into other cord levels, however, provide some evidence for a small representation of the leg and/or lower trunk, in addition to the arm representation in the PMv. Finally, we found the surprising result that lower cervical segments receive dense input from two spatially separate regions of area 4 . This observation raises questions about the classic map of the arm in area 4 and suggests that the primary motor cortex contains at least two hand representations.

Brief reports of some of the data presented here have appeared previously (He et al., 1989, 1990).

\section{Materials and Methods}

The present study is based on observations from nine pig-tailed macaques (Macaca nemestrina, 4-6 kg) (Table 1). In two of the animals, corticospinal neurons projecting to lower thoracic or sacral segments were labeled by placing crystals of horseradish peroxidase (HRP) into the dorsolateral funiculus at either $\mathrm{T} 7$ or $\mathrm{S} 2$. The surgical and histological procedures used in these two cases have been described in a previous publication (Dum and Strick, 1991b) and will not be repeated here.

In the remaining seven animals, the topographic organization of corticospinal neurons in the frontal lobe was examined by injecting the fluorescent tracers fast blue (FB; $5 \%$ in distilled water) and diamidino yellow (DY; $2 \%$ in distilled water) into the gray matter at different segmental levels in the same animal. We used two protocols in the experiments with fluorescent tracers (Table 1). In one set of experiments $(n=5)$, we injected one of the fluorescent tracers into upper cervical segments $(\mathrm{C} 2-\mathrm{C} 4)$ and then injected the other fluorescent tracer into lower cervical segments (C7-T1). In another set of experiments $(n=2)$, we injected one of the fluorescent tracers into lower lumbosacral segments (L6-S1) and then a week later injected the other fluorescent tracer into lower cervical segments (C7-T1). We used a 1 week delay between tracer injections to allow additional time for transport from the more remote segments in the lumbosacral spinal cord to cerebral cortex. The general procedures for these experiments were thoroughly described in our prior publication in which wheat germ agglutinin conjugated to horseradish peroxidase was used as a tracer (Dum and Strick, 1991b).

\section{Surgical procedures}

Each animal was pretreated with dexamethasone $(0.5 \mathrm{mg} / \mathrm{kg}, \mathrm{i} . \mathrm{m})$. $15 \mathrm{hr}$ prior to the surgery and was initially anesthetized with ketamine $(10 \mathrm{mg} / \mathrm{kg}$, i.m.) and Nembutal $(20 \mathrm{mg} / \mathrm{kg}$, i.p.). Additional doses of ketamine $(5-10 \mathrm{mg} / \mathrm{kg})$ and Nembutal $(5 \mathrm{mg} / \mathrm{kg})$ were given as needed to maintain anesthesia. During surgery, each animal was given atropine $(0.1 \mathrm{mg} / \mathrm{kg}$ ) and antibiotics (Kefzol, $25 \mathrm{mg} / \mathrm{kg}$, every $6 \mathrm{hr}$; Oxycillin, 25 $\mathrm{mg} / \mathrm{kg}$, every $4 \mathrm{hr}$; gentamycin, $1 \mathrm{mg} / \mathrm{kg}$, every $8 \mathrm{hr}$ ) and was hydrated with intravenous fluids (lactated Ringers, approximately 10-20 cc/hr). Respiration, heart rate, body temperature, and urinary output were monitored. Body temperature was maintained with a heating pad.

All surgical procedures were performed using sterile technique. A laminectomy was performed over the appropriate segmental level of the spinal cord. The dura was opened and the surface of the spinal cord was kept moist by covering it with warmed saline and a thin sheet of Silastic. Tracer was injected into the gray matter using a $5 \mu \mathrm{l}$ Hamilton syringe. Eight to ten penetrations spaced about $1.5 \mathrm{~mm}$ apart were made to ensure that the injections included all appropriate spinal segments. To prevent damage to the dorsolateral funiculus where most of the corticospinal tract travels, the syringe needle was tilted to pass through the dorsal columns and entered the spinal cord at an angle. The angle and the depth of the syringe required to reach the intermediate zone and ventral horn of the spinal cord were adjusted for each segment. We attempted to fill the gray matter of the spinal cord with tracer by making injections at two different depths along each tract (FB, $0.2 \mu \mathrm{l} / \mathrm{depth}$; DY, $0.3 \mu \mathrm{l} /$ depth). The total amount of tracer injected at each segmental level for each animal is listed in Table 1 and ranged from 2.8 to $3.2 \mu \mathrm{l}$ for FB and from 4.0 to $7.2 \mu \mathrm{l}$ for DY.

Upon the completion of each injection, the Hamilton syringe was left in place for at least 1-2 min. When all the injections at a segmental level were completed, the spinal cord was covered with a thin sheet of surgical-grade Silastic and Gelfoam. Then, the wound was closed in layers. At the completion of surgery, the animal was returned to its home cage and its recovery was carefully monitored.

After the appropriate survival time (Keizer et al., 1983; Craig et al., 1989; Keizer and Kuypers, 1989) (see Table 1), each monkey was deeply reanesthetized with ketamine $(20 \mathrm{mg} / \mathrm{kg}$, i.m.) and Nembutal $(36 \mathrm{mg} /$ $\mathrm{kg}$, i.p.). Then, the animal was perfused transcardially using a threestage procedure (see Rosene and Mesulam, 1978; Mesulam, 1982). The perfusates included (1) $0.1 \mathrm{~m}$ phosphate buffer ( $\mathrm{pH} 7.4$ ), (2) $4 \%$ paraformaldehyde in $0.1 \mathrm{~m}$ phosphate buffer, and (3) $4 \%$ paraformaldehyde 

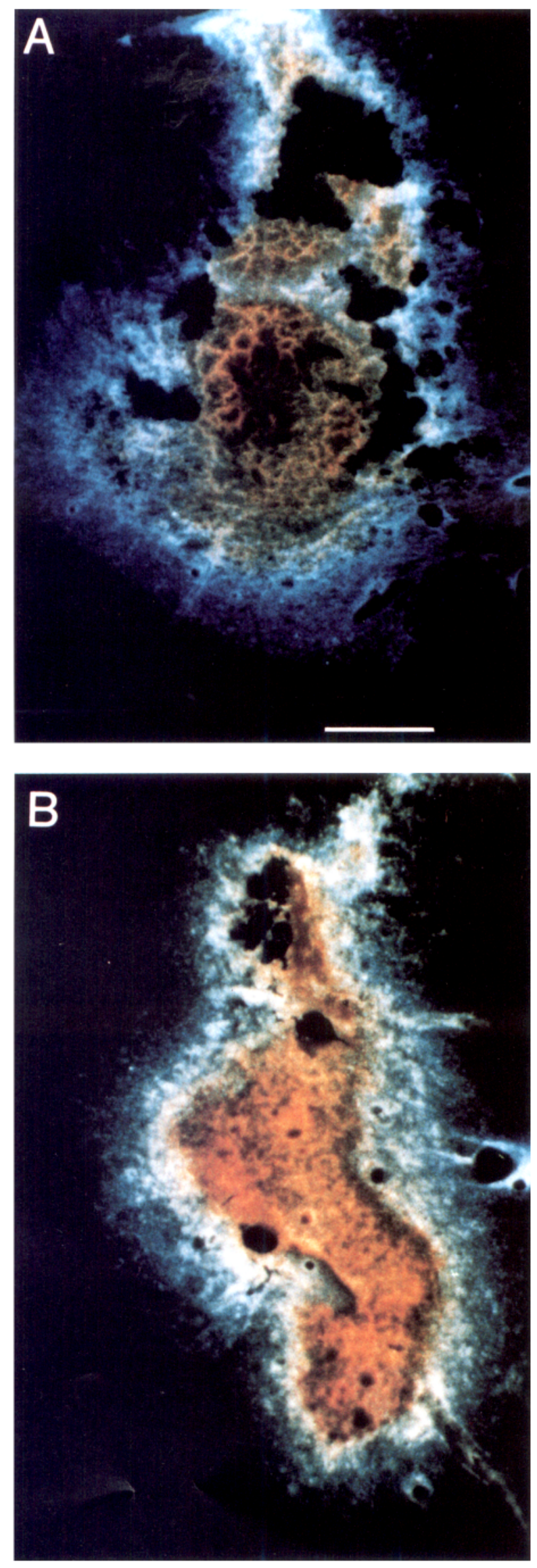
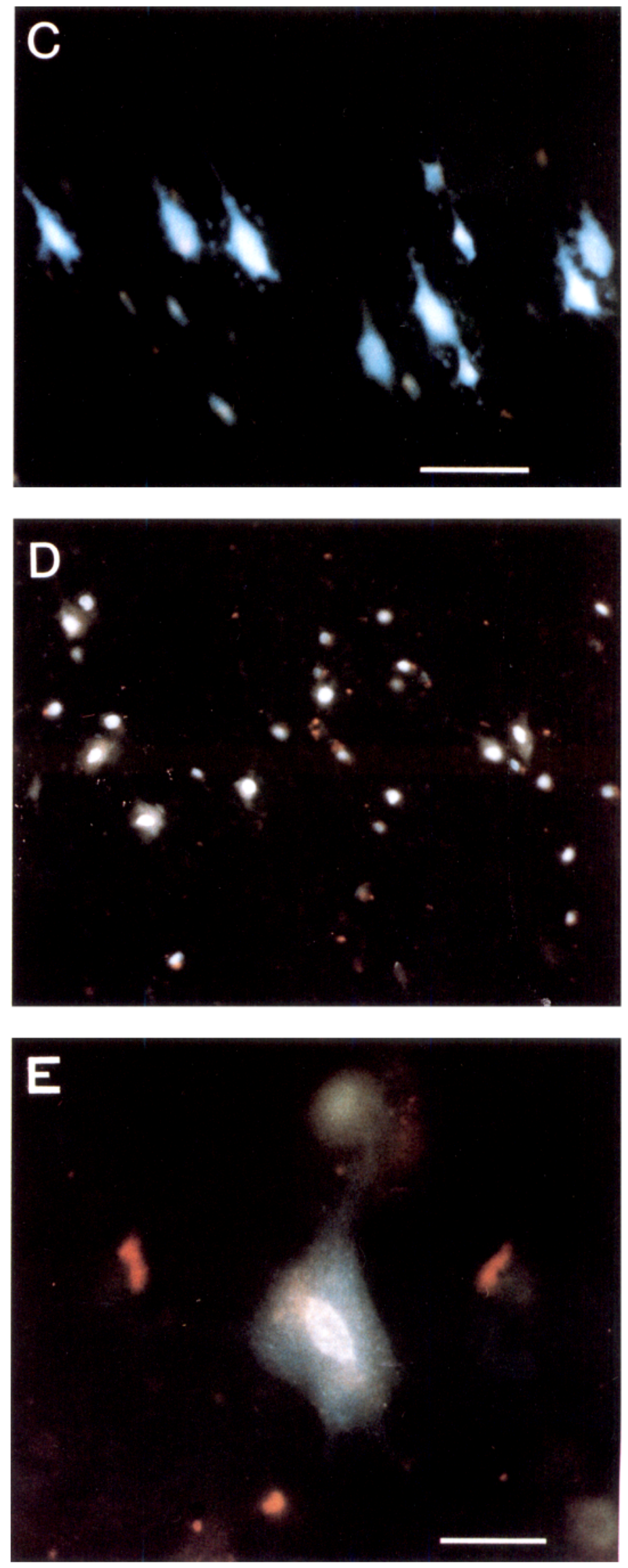
$\mathrm{H2}$ C7

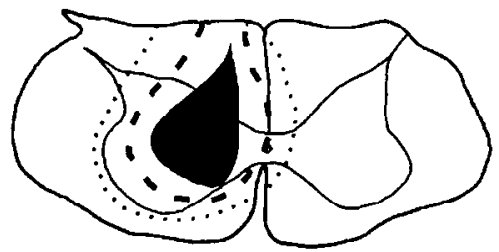

C8

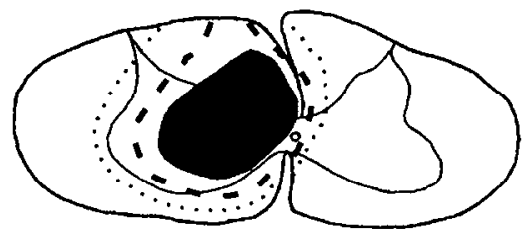

T1

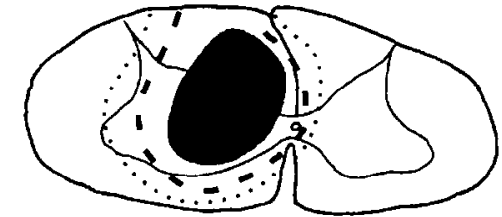

FB injection sites

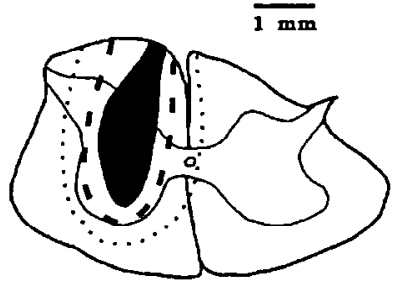

L6

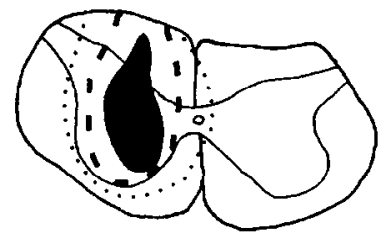

L7

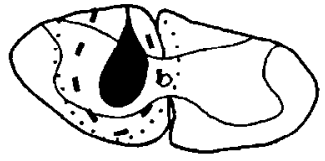

S1

DY injection sites
Figure 2. Cross sections through the injected spinal segments of monkey $\mathrm{H} 2$. The shaded region indicates zone I of the injection site. Zones II and III of the injection site are indicated by the dashed and the dotted lines (see Materials and Methods for the definition of the three zones of fluorescent labeling). in $0.1 \mathrm{M}$ phosphate buffer with $10 \%$ glycerin. Following the perfusion, the brain and spinal cord were removed from the animal. The brain was cut into a large block that included the arcuate sulcus (ArS) rostrally and the intraparietal sulcus caudally. The spinal cord was cut into blocks that included at least one segment rostral and caudal to the injection sites. Then, the brain and spinal cord blocks were stored in buffered $4 \%$ paraformaldehyde with $20 \%$ glycerin and $2 \%$ dimethyl sulfoxide at $4^{\circ} \mathrm{C}$.

\section{Histological procedures}

Four to seven days later, the spinal cord blocks containing the injection sites and the large brain block were quickly frozen (Rosene et al., 1986). Serial coronal sections $(50 \mu \mathrm{m})$ of these blocks were cut on a microtome. Every 10th section of cortex and spinal cord was postfixed and counterstained with cresyl violet for cytoarchitectonic analysis (see procedure outlined by Gower in Mesulam, 1982). The remaining sections were immediately mounted from distilled water onto clean gelatin-coated slides to prevent migration of tracer out of labeled neurons (Bentivoglio et al., 1980; Kuypers and Huisman, 1984). Mounted sections were air dried and stored uncoverslipped in the dark at $4^{\circ} \mathrm{C}$ (Huisman et al., 1983).

\section{Analytical procedures}

Sections from the experiments using HRP as a tracer were examined under bright-field and/or dark-field, polarized illumination. Sections from the experiments using FB and DY were examined using fluorescent illumination (Leitz filter D, 355-425 nm excitation wavelength). Injection sites, section outlines, and labeled neurons were plotted using a computer-based charting system (MD2, Minnesota Datametrics). This system uses optical encoders to sense $x-y$ movements of the microscope stage and stores the coordinates of charted structures. At least every 10 th spinal cord section through the injected segments was examined to determine the spread of tracer. As in other studies (Huisman et al., 1983; Kuypers and Huisman, 1984; Conde, 1987), three concentric zones of fluorescent labeling could be defined in the spinal cord following the FB and DY injections (Figs. 1, 2). The central zone, zone I, was defined as the region surrounding the needle track that contained an almost solid mass of fluorescent material. In general, the zone I of FB injections was larger than that of DY injections. The intermediate zone, zone II, was defined as the region that contained large numbers of intensely fluorescent neurons and glia. Zone II gradually changed into a peripheral zone, zone III, that contained some background tissue fluorescence and weakly fluorescent neurons and glia. Prior studies have indicated that the effective area of uptake and transport of FB and DY is confined to zones I and II (e.g., Huisman et al., 1983; Kuypers and Huisman, 1984; Conde, 1987). Therefore, we have defined the "injection sites" as including only these zones.

At least every fourth cortical section through the frontal lobe was plotted to determine the distribution of corticospinal neurons. In all animals, some glial labeling was seen surrounding intensely labeled FB neurons (Fig. 1C). However, we had no difficulty distinguishing this labeling from that of corticospinal neurons. The type of glial staining we observed is believed to be evidence of tracer leakage from labeled neurons (Keizer et al., 1983; Conde, 1987). We saw no evidence of any further tracer movement (e.g., from glial to other neurons). Other studies using methods similar to ours have reported comparable observations (e.g., Innocenti, 1981; Rosina, 1982; Weidner et al., 1983; Conde, 1987; Craig et al., 1989). Thus, the glial labeling that occurred in the present study does not appear to confound our results.

The charts of every fourth cortical section were used to reconstruct the distribution of labeled neurons on the lateral surface of the frontal lobe. We began this process by aligning the charts of individual sections on the junction of the lateral surface with the medial wall of the hemisphere. Then, three different types of computer reconstructions were prepared.

Flattened maps. The lateral surface of the frontal lobe was unfolded by "straightening" layer V of the cortex (for a complete description, see Dum and Strick, 1991b). The process of flattening included the rostral bank of the central sulcus (CS) and both banks of the superior precentral sulcus (SPcS), but not the arcuate sulcus (ArS). During flattening, the SPcS was "stretched" laterally in the animals that received tracer injections into lumbar segments of the spinal cord (e.g., Figs. 5, 7). This procedure retained the normal spatial relationships in the "leg" area of the primary motor cortex, but induced $2-3 \mathrm{~mm}$ of distortion in the "arm" area lateral to the SPcS. In animals with injection sites limited

Figure 1. Photomicrographs of spinal cord injection sites and corticospinal neurons labeled with fluorescent tracers. These photomicrographs were taken under $360 \mu \mathrm{m}$ excitation wavelength. $A$, An FB injection site. This injection site is drawn in Figure $2, \mathrm{C} 7, B, \mathrm{~A}$ DY injection site. This injection site is drawn in Figure 2, L6. C, FB-labeled corticospinal neurons. Note the presence of cytoplasmic labeling. $D$, DY-labeled corticospinal neurons. Note the presence of largely nuclear labeling. E, A "double-labeled" corticospinal neuron. DY is present in the nucleus and FB is present in the cytoplasm. Few glial cells were labeled by either FB or DY. Scale bars: $A, 300 \mu \mathrm{m}$ for $A$ and $B ; C, 100 \mu \mathrm{m}$ for $C$ and $D ; E, 25 \mu \mathrm{m}$. 

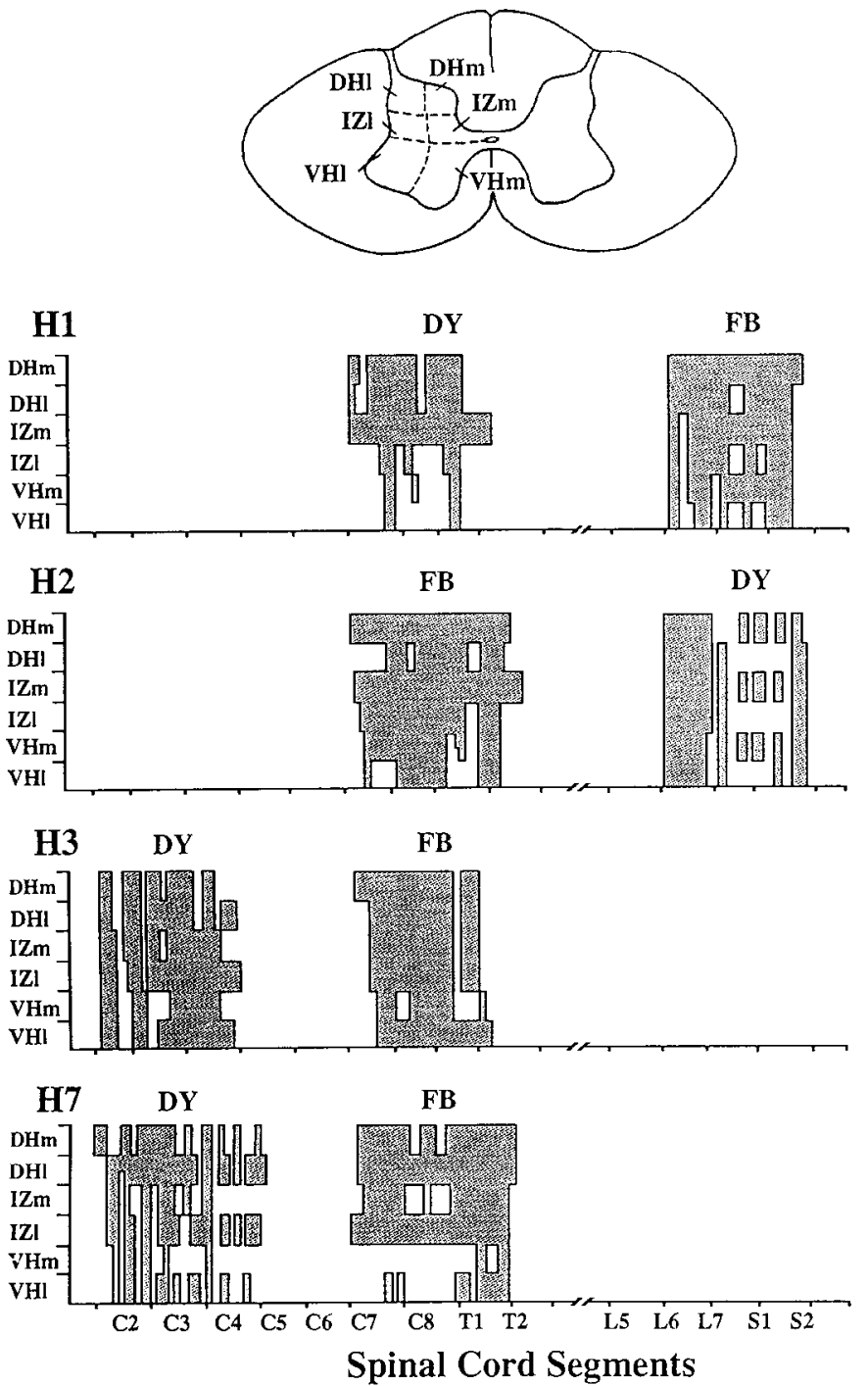

Figure 3. Segmental extent of injection sites. Top, A cross section through $\mathrm{C} 8$. Six regions of the gray matter that were evaluated for their involvement in the injection site: medial $(m)$ and lateral $(l)$ regions of the dorsal horn $(D H)$, the intermediate zone $(I Z)$, and the ventral horn $(V H)$. Bottom, Segmental spread of fluorescent tracer within the gray matter in four representative animals. $D Y$, diamidino yellow labeling; $F B$, fast bluc labcling.

to cervical segments, the normal spatial relationships in the "forelimb" area were retained by stretching the SPcS medially (see Figs. 9, 10, 1215). The arcuate sulcus, because of its complexity, was not unfolded in this manner. Labeled neurons in the ArS will be indicated by arrows that point to the bank of the sulcus where the neurons were located.

Density maps. After flattening, layer $\mathrm{V}$ of each section was divided into $200 \mu \mathrm{m}$ bins. The number of neurons labeled with a particular tracer was then counted in each bin and assigned a color code (see Figs. $7,12,13$ ). Four color levels were used, with the white, yellow, and red reserved, in descending order, for the upper $20 \%$ of the total sample of bins. The upper $20 \%$ of bins contained approximately $45-50 \%$ of the total labeled neurons and were considered "high-density" bins.

Accurately determining the cell density for bins located in the central sulcus was complicated by the fact that coronal sections through the sulcus cut layer $\mathrm{V}$ at an angle. This effectively results in sampling a larger width of this layer. To correct for this bias, the number of labeled neurons in each bin located in the central sulcus was multiplied by the cosine of the angle formed by the sulcus and the midline of the hemisphere. No other stereological corrections were applied to our data.

Overlap maps. To generate these maps (e.g., Fig. 14) the type of labeled neurons in each $200 \mu \mathrm{m}$ bin was given a color code. Bins containing only FB-labeled neurons were coded blue, bins containing only DYlabeled neurons were coded yellow, and bins with both FB and DY neurons were coded red (= overlap bins). Then, the extent of overlap of cortical regions containing FB-labeled neurons with those containing DY-labeled neurons was quantitatively analyzed by calculating the percentage of overlap bins in each motor area (data presented in Tables 2 4).

\section{Cytoarchitectonic analysis}

The location of layer $\mathrm{V}$ neurons with mean diameters greater than 29 $\mu \mathrm{m}$ (Weinrich and Wise, 1982) was charted on every Nissl-stained section through the frontal lobe (i.e., every 10 th section). Then, layer $\mathrm{V}$ was divided into $200-\mu \mathrm{m}$-wide bins and the number of neurons in each bin was determined. These bins were color coded and plotted on an unfolded map of the frontal lobe. The change in the density of large neurons in layer $V$ was used to draw the border between areas 4 and 6 (Weinrich and Wise, 1982; Kurata and Tanji, 1986). The location of this border corresponds closely to that defined in other anatomical and physiological studies of the macaque frontal lobe (e.g., Sessle and Wiesendanger, 1982; Tanji and Kurata, 1982; Weinrich and Wise, 1982; Kurata and Tanji, 1986).

\section{Results}

\section{Location and extent of injection sites}

To illustrate our findings, we will present the results of five representative animals: $\mathrm{H} 1, \mathrm{H} 2, \mathrm{H} 3, \mathrm{H} 7$, and $\mathrm{K} 3$. In $\mathrm{H} 1-\mathrm{H} 7$, fluorescent tracers were injected into the gray matter of the spinal cord. In K3, HRP was placed into the dorsolateral funiculus at the seventh thoracic segment. The types of tracers, the location of tracer injections, the amount of tracer injected, and the survival times used for these experiments are summarized in Table 1.

As noted in Materials and Methods, injections of fluorescent tracers into the gray matter were made by passing the syringe needle through the dorsal columns. As a result, we were able to avoid any significant damage or spread of tracer into the dorsolateral funiculus where the majority of corticospinal axons travel. However, in all animals, there was some spread of tracer from the injection site into adjacent parts of the ventral funiculus and into the needle track in the dorsal columns (Fig. 2).

We examined every 10 th section through the appropriate spinal segments (Fig. 3) and mapped the segmental spread of tracer within the spinal gray matter (Fig. 3, top). In general, we found that the tracers were largely confined to the segments injected (Fig. 3). The most complete injection site in the lower cervical segments (C7, C8, and T1) was found in $\mathrm{H} 3$ (Fig. 3). In this animal, tracer involved almost all of the gray matter of the injected segments. Small portions of the gray matter did not contain tracer in the other three animals with injections into the lower cervical segments $(\mathrm{H} 1, \mathrm{H} 2$, and $\mathrm{H} 7)$. For example, in $\mathrm{H} 7$, the injection site included large portions of the dorsal horn and the intermediate zone throughout segments $\mathrm{C} 7, \mathrm{C} 8$, and $\mathrm{T} 1$, but substantially involved the ventral horn only at $\mathrm{T} 1$.

The lower lumbosacral segments (L6-S1) were injected with tracer in $\mathrm{H} 1$ and $\mathrm{H} 2$ (Fig. 3). The injection site was most complete in $\mathrm{H} 1$ and involved almost all of the gray matter of L6, L7, and S1. In H2, tracer filled the gray matter of L6, rostral L7, and caudal S1 but incompletely involved caudal L7 and rostral $\mathrm{S} 1$.

The uppcr ccrvical scgments (C2-C4) were injected with tracer in $\mathrm{H} 3$ and $\mathrm{H} 7$ (Fig. 3). The injection site was most complete in $\mathrm{H} 3$ and involved large portions of $\mathrm{C} 2, \mathrm{C} 3$, and $\mathrm{C} 4$. In $\mathrm{H} 7$, the injection site largely filled the gray matter of $\mathrm{C} 2$ and $\mathrm{C} 3$ and partially involved C4.

In general, more neurons were labeled after DY injections 
Table 1. Experimental protocols

\begin{tabular}{|c|c|c|c|c|c|c|}
\hline $\begin{array}{l}\text { Ani- } \\
\text { mal }\end{array}$ & Tracer & $\begin{array}{l}\text { Segments } \\
\text { of } \\
\text { spinal cord }\end{array}$ & $\begin{array}{l}\text { Amount } \\
\text { per } \\
\text { injec- } \\
\text { tion } \\
(\mu 1)\end{array}$ & $\begin{array}{l}\text { Num- } \\
\text { ber of } \\
\text { injec- } \\
\text { tions }\end{array}$ & $\begin{array}{l}\text { Total } \\
\text { injected } \\
\text { amount } \\
(\mu \mathrm{l})\end{array}$ & $\begin{array}{l}\text { Sur- } \\
\text { vi- } \\
\text { val } \\
\text { time } \\
\text { (d) }\end{array}$ \\
\hline \multirow[t]{2}{*}{ H1 } & $2 \% \mathrm{DY}$ & C7-T1 & 0.3 & 24 & 7.2 & 21 \\
\hline & $5 \%$ FB & L6-S1 & 0.2 & 16 & 3.2 & 30 \\
\hline \multirow[t]{2}{*}{$\mathrm{H} 2$} & $5 \% \mathrm{FB}$ & C7-T1 & 0.2 & 16 & 3.2 & 17 \\
\hline & $2 \% \mathrm{DY}$ & L6-S1 & 0.3 & 18 & 5.4 & 24 \\
\hline \multirow[t]{2}{*}{$\mathrm{H} 3$} & $2 \%$ DY & $\mathrm{C} 2-\mathrm{C} 4$ & 0.25 & 18 & 4.5 & 18 \\
\hline & $5 \%$ FB & $\mathrm{C} 7-\mathrm{T} 1$ & 0.2 & 14 & 2.8 & 18 \\
\hline \multirow[t]{2}{*}{$\mathrm{H} 4$} & $5 \% \mathrm{FB}$ & $\mathrm{C} 2-\mathrm{C} 4$ & 0.2 & 16 & 3.2 & 16 \\
\hline & $2 \% \mathrm{DY}$ & C7-TI & 0.25 & 14 & 3.5 & 16 \\
\hline \multirow[t]{2}{*}{ H5 } & $2 \% \mathrm{DY}$ & $\mathrm{C} 2-\mathrm{C} 4$ & 0.25 & 16 & 4.0 & 18 \\
\hline & $5 \%$ FB & C7-T1 & 0.15 & 16 & 2.4 & 18 \\
\hline \multirow[t]{2}{*}{ H6 } & $2 \% \mathrm{DY}$ & $\mathrm{C} 2-\mathrm{C} 4$ & 0.3 & 16 & 4.8 & 15 \\
\hline & $5 \% \mathrm{FB}$ & C7-T1 & 0.175 & 16 & 2.8 & 15 \\
\hline \multirow[t]{2}{*}{ H7 } & $2 \% \mathrm{DY}$ & $\mathrm{C} 2-\mathrm{C} 4$ & 0.3 & 20 & 6.0 & 15 \\
\hline & $5 \% \mathrm{FB}$ & C7-T1 & 0.175 & 16 & 2.8 & 15 \\
\hline K3 & HRP & $\mathrm{T} 7$ & Crystal & & & 5 \\
\hline $\mathrm{K} 4$ & HRP & $\mathrm{S} 2-\mathrm{S} 3$ & Crystal & & & 5 \\
\hline
\end{tabular}

than after FB injections. Iowever, this was not always the case. For example, in both $\mathrm{H} 3$ and $\mathrm{H} 7$, DY was injected into upper cervical segments and FB was injected into lower cervical segments. In the primary motor cortex of $\mathrm{H} 3$, the ratio of neurons labeled by the upper cervical injections to those labeled by the lower cervical injections was approximately 1.45:1. In contrast, in the primary motor cortex of $\mathrm{H} 7$ this ratio was approximately $0.55: 1$. Thus, the type of tracer injected was not the only factor influencing the number of neurons labeled. For this reason, we will largely avoid numerical comparisons between injection sites. Instead, we will focus on the topographic distribution of labeled neurons. There was no evidence that this feature was affected by the use of different tracers and changes in the total number of labeled neurons.

\section{Topographic distribution of corticospinal neurons}

As in prior studies, we found substantial numbers of corticospinal neurons in three motor areas on the lateral surface of the hemisphere (Fig. 4, bottom; for references, see Dum and Strick, $1991 \mathrm{~b}$ ). One of these was the premotor area that is in and adjacent to the caudal bank of the ArS at its inferior limb (Fig. 4 , bottom). In our previous publications we referred to this cortical region as the arcuate premotor area (APA). Other investigators have included the APA within the post-arcuate area (Matsumura and Kubota, 1979; Godschalk et al., 1984), a portion of areas $F 4$ and $F 5$ (Matelli et al., 1985), area $6 \mathrm{Va}$ (Barbas and Pandya, 1987), the postarcuate premotor/motor area, $P M a$ (Humphrey and Tanji, 1991), and the ventral premotor area, $P M v$ (Wise et al., 1991). To reduce the potential confusion that arises from differences in terminology, we will refer to this region as the ventral premotor area $(P M v)$.

The second region containing corticospinal neurons was the premotor area in and adjacent to the SPcS (Fig. 4, bottom). This region has been included within area $6 a \alpha$ (Vogt and Vogt, 1919), area $F 2$ (Matelli et al., 1985), area $6 D C$ (Barbas and Pandya, 1987), and the dorsal (superior) premotor area, $P M d$ (Humphrey

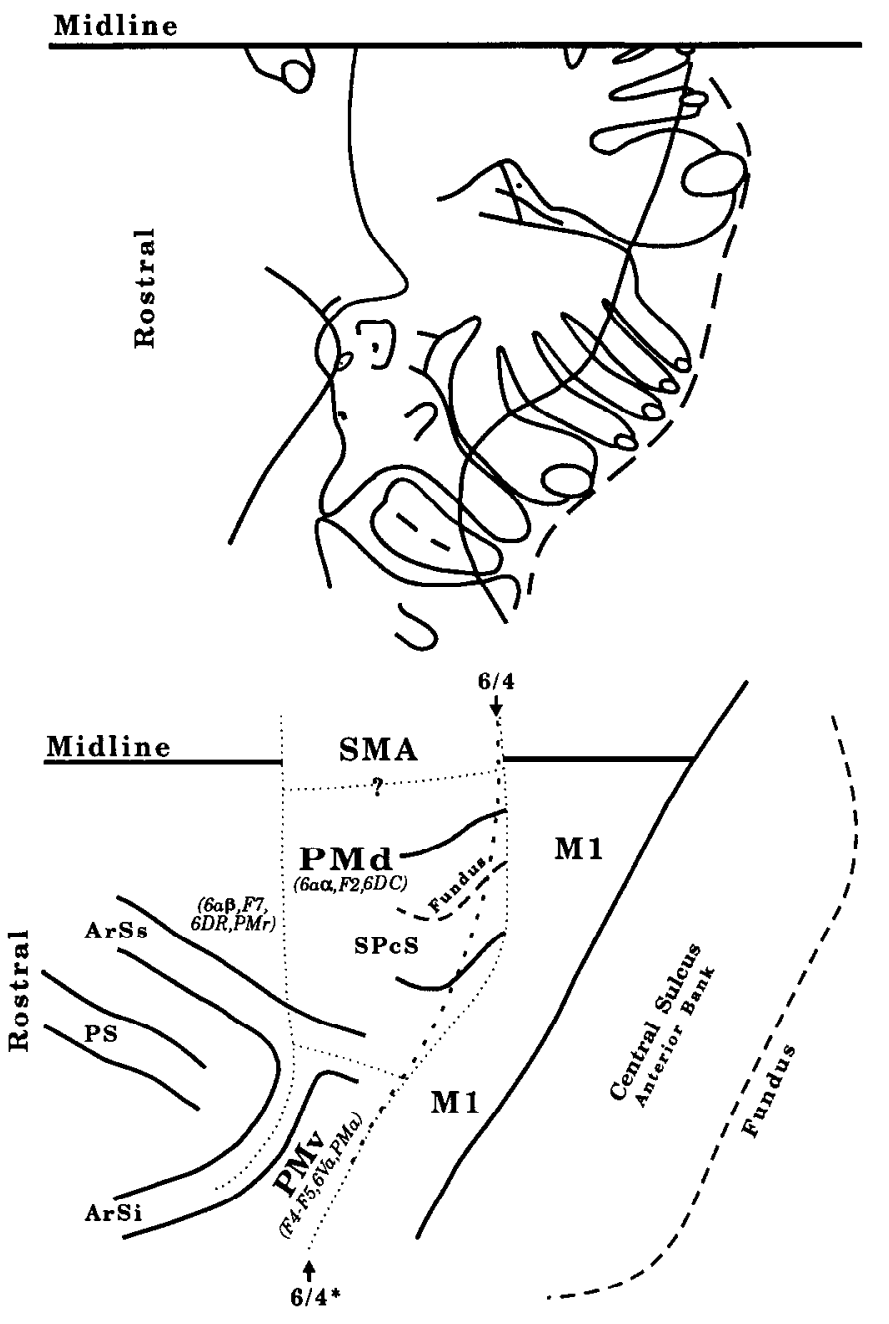

Figure 4. Motor areas on the lateral surface of the frontal lobe. Top, Classic map of body representation in the primary motor cortex of the macaque (adapted from Woolsey et al., 1952). Bottom, Location of the premotor areas on the lateral surface of the frontal lobe. The letlers and numbers in the parentheses below PMv, PMd, and rostral to PMd indicate the other designations that have been applied to these cortical areas (see Results for further explanation). Thin dotted lines indicate the boundaries between the premotor areas and the primary motor cortex. A thick dotted line indicates the border between areas 4 and 6 as determined by a change in the density of large neurons in layer $V$. Note that we have adopted a modified border $\left(6 / 4^{*}\right)$ that includes the SPcS (see Results for explanation). The fundus of the CS and the SPcS are indicated by dashed lines. ArSi, inferior limb of the ArS; ArSs, superior limb of the ArS; $M 1$, primary motor cortex; $P S$, principal sulcus.

and Tanji, 1991; Wise et al., 1991). We will refer to this region as the dorsal premotor area $(P M d)$.

The third motor area on the lateral surface of the hemisphere that contained large numbers of corticospinal neurons was the primary motor cortex (Fig. 4, bottom). With one exception, we have adopted the generally accepted definition that the anterior limit of the primary motor cortex is the border between areas 4 and 6 (e.g., Sessle and Wiesendanger, 1982; Weinrich and Wise, 1982; Kurata and Tanji, 1986). This border was drawn for each animal based on the change in the density of large neurons in layer $V$ (see Materials and Methods). It should be noted, however, that we have included all of the cortex lying within the SPcS as part of the PMd (6/4* in Fig. 4, bottom). Although this region of cortex has a moderate number of large 

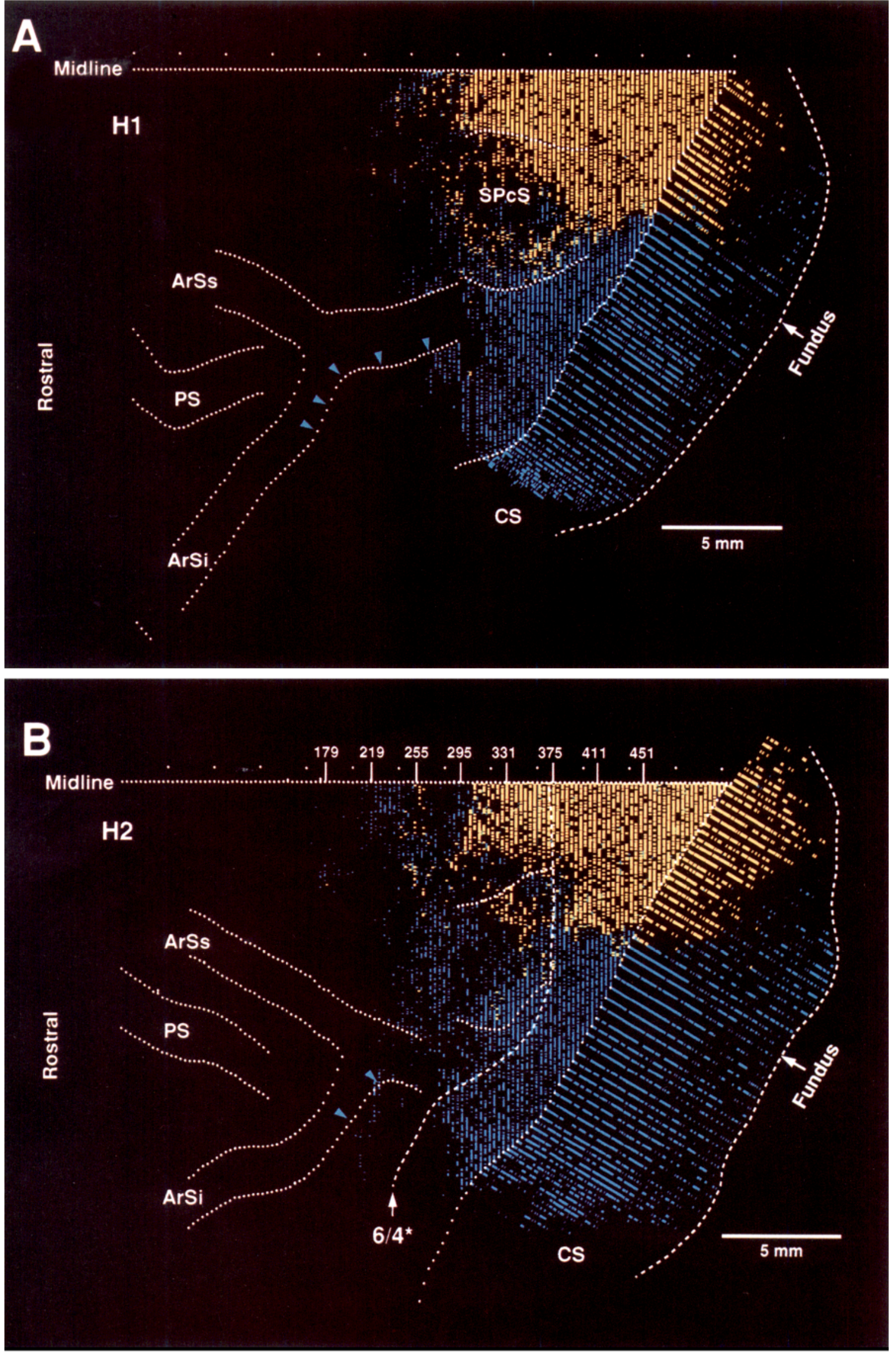
neurons in layer V (Dum and Strick, 1991b), the results of singleneuron recording studies in trained monkeys suggest that it should be included within the "premotor cortex" (i.e., PMd; see Kurata et al., 1985; Kurata and Wise, 1988a,b; Kurata, 1989).

Corticospinal neurons also were found medially on the lateral surface of the hemisphere, in a portion of area 6 that is rostral to the hindlimb representation in area 4 (Fig. 4, bottom). This cortical region is thought to be a dorsolateral extension of the supplementary motor area (SMA; for references, see Woolsey et al., 1952; Wise and Tanji, 1981; Mitz and Wise, 1987; Luppino et al., 1991; Matelli et al., 1991). The topographic distribution of corticospinal neurons within the SMA and other premotor areas on the medial wall will be presented in a subsequent report (S.-Q. He, R. P. Dum, and P. L. Strick, unpublished observations).

In all of our experiments, very few labeled neurons $(<0.5 \%)$ were found in the region of area 6 that is located medial to the superior limb of the ArS and rostral to the genu of the ArS. According to the terminologies employed in other studies (Fig. 4 , bottom), this region appcars to correspond largely to area $6 a \beta$ (Vogt and Vogt, 1919), area 6DR (Barbas and Pandya, 1987), area $F 7$ (Luppino et al., 1991; Matelli et al., 1991), and a rostral part of the premotor cortex $(P M)$ (e.g., Pellegrino and Wise, 1991). Although there is evidence that this portion of area 6 may have a motor function, the connections of this part of area 6 suggest that it should not be regarded as one of the premotor areas (for a discussion on this point, see Dum and Strick, 1991b).

The remainder of the results has been divided into two sections. In the first, we will present the results from animals with tracer injections into lower cervical and lower lumbosacral segments $(\mathrm{H} 1, \mathrm{H} 2)$. This section will also include a description of the distribution of labeled neurons after the placement of HRP into the dorsolateral funiculus at T7 (K3). To a large extent, the observations in $\mathrm{H} 1, \mathrm{H} 2$, and $\mathrm{K} 3$ allow us to compare the location of corticospinal neurons that influence the control of "arm" movements with the location of corticospinal neurons that influence the control of "leg" movements. In the second section, we will present the results from animals with tracer injections into upper cervical and lower cervical segments $(\mathrm{H} 3, \mathrm{H} 7)$. We will argue that, with one important exception, the observations in these animals allow us to compare the location of corticospinal neurons that influence the control of hand movements with the location of corticospinal neurons that influence the control of more proximal parts of the forelimb (see Discussion). Since largely distinct patterns of corticospinal labeling were observed in the primary motor cortex, PMv, and PMd, we will describe the topographic distribution of labeled neurons in each motor area separately.

\section{Comparison of corticospinal projections to lower cervical and lower lumbosacral segments}

Primary motor cortex. We found that the area 4 neurons that project to lower cervical segments were quite separate from those that project to lower lumbosacral segments [Figs. 5, 6 (sections 295-451), 7]. Corticospinal neurons projecting to lower
$\mathrm{H} 2$

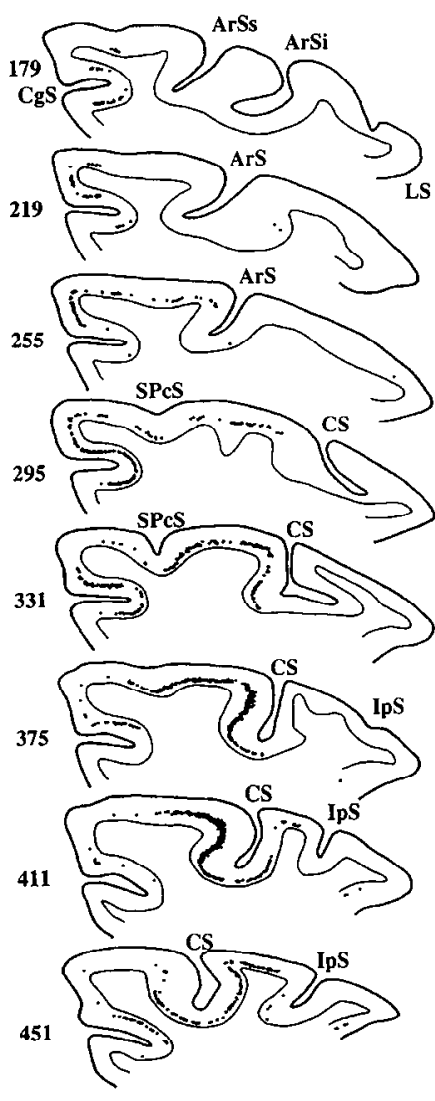

DY (L6-S1)

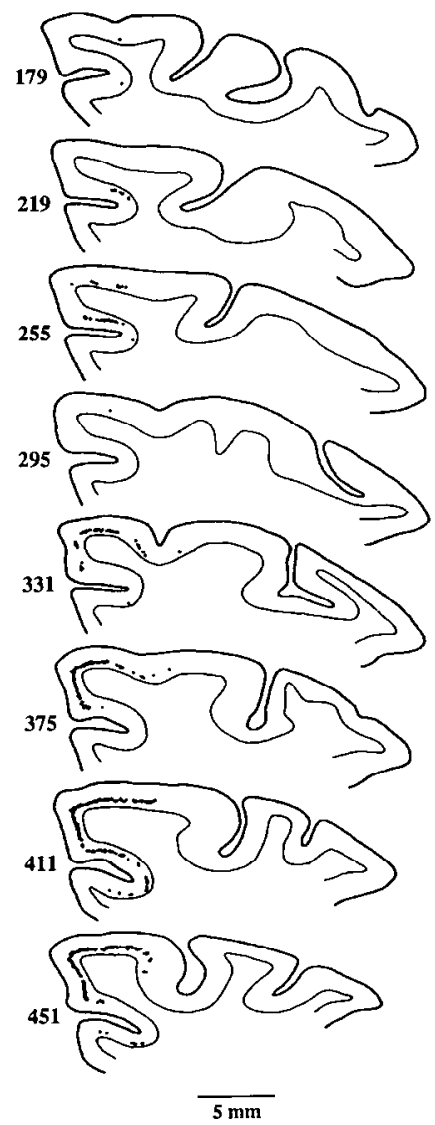

Figure 6. Plots of labeled neurons in animal H2. The level of each coronal section is indicated by the number to the left of each diagram. The location of each section in the frontal lobe is indicated by the numbered lines in Figure $5 B$. In this animal, FB was injected into lower cervical segments (C7-T1) and DY was injected into lower lumbosacral segments (L6-S1). The injection sites are illustrated in Figures 1-3. Note that corticospinal neurons that project to lower cervical segments are largely scparated from those that project to lower lumbosacral scgments. $\mathrm{CgS}$, cingulate sulcus; $I p S$, intraparietal sulcus; $L S$, lateral sulcus. See Figure 4 for details and further abbreviations.

cervical segments were located on both the precentral gyrus and the anterior bank of the CS. On the precentral gyrus, ncurons projecting to lower cervical segments were found as far as $2-3$ mm lateral to the spur of the ArS and extended as far medially as the level of the SPcS.' Within the anterior bank of the sulcus,

\footnotetext{
1. Note that the SPcS has been unfolded laterally in the surface reconstructions that display the data from $\mathrm{H} 1$ and $\mathrm{H} 2$ (Figs. 5, 7). Lateral unfolding was chosen for these maps to create as little distortion as possible in the medial regions of cortex where the arm and leg representations of primary motor cortex abut one another. However, this type of map does introduce some distortion in the lateral portion of the arm representation. As a consequence, the corticospinal projections to cervical segments appear to originate from cortical regions $2-3 \mathrm{~mm}$ more laterally than is actually the case. A more accurate representation of the lateral extent of arm representation in the primary motor cortex is displaycd in Figures 9,10 , and 13-16, where the SPCS has been unfolded medially
}

Figure 5. Maps of corticospinal neurons projecting to lower cervical and lower lumbosacral segments. $A$, The distribution of labeled corticospinal neurons in animal H1. B. The distribution of labeled corticospinal neurons in animal $\mathrm{H} 2$. Every fourth coronal section was plotted to construct these maps. Yellow dots, neurons that project to lower lumbosacral segments (L6-S1); blue dots, neurons that project to lower cervical segments (C7-T1). In $\mathrm{H} 1$ and $\mathrm{H} 2$, the inferior limb of the ArS (ArSi) contains a small number of neurons that project to lower cervical segments. The location of these neurons is indicated by blue arrowheads. The SPcS has been unfolded laterally to display the corticospinal neurons that are buried within this sulcus. See Figure 4 for details and further abbreviations. 


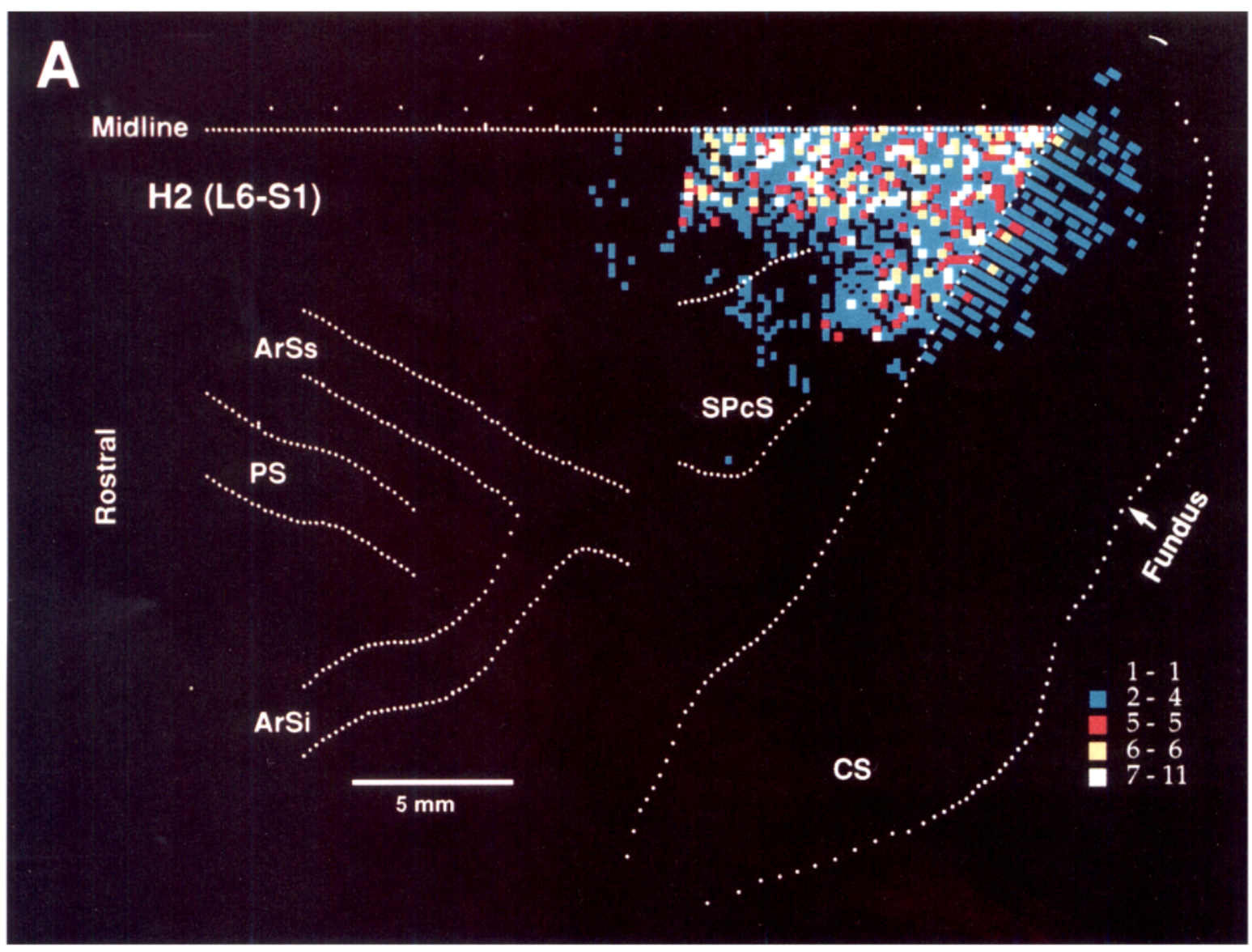

B

Midline

$\mathrm{H} 2$ (C7-T1)

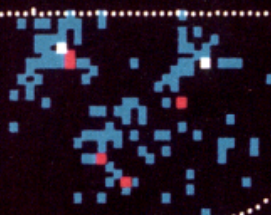

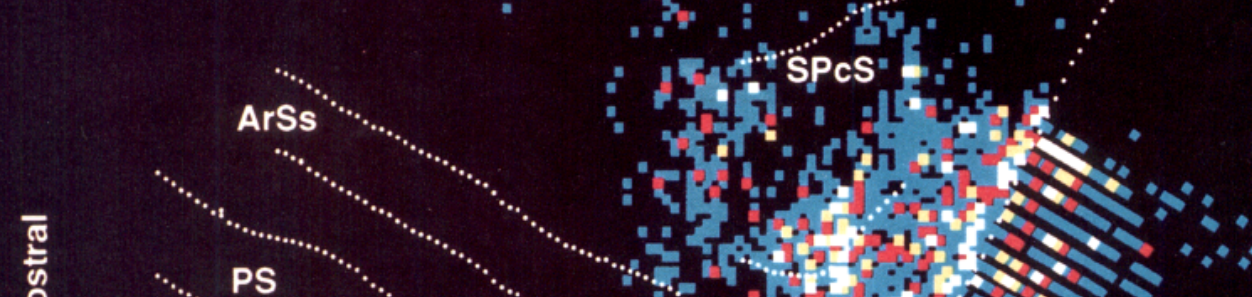

के

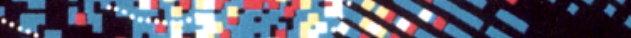

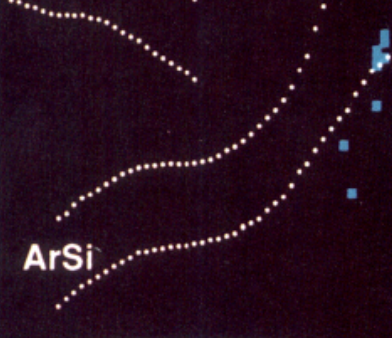

$5 \mathrm{~mm}$

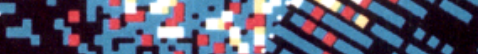
Thi

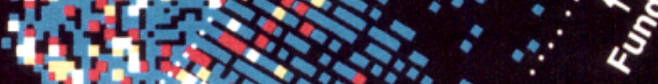
n?:

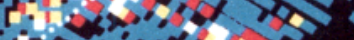
isteing:? isis:

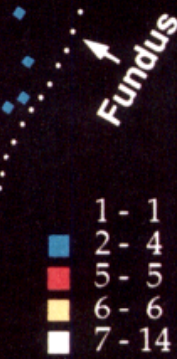


Table 2. Distribution of corticospinal neurons projecting to lower cervical (C7-T1) and lower lumbosacral (L6-S1) segments

\begin{tabular}{|c|c|c|c|c|c|c|}
\hline & \multicolumn{2}{|l|}{ M1 } & \multicolumn{2}{|l|}{ PMd } & \multicolumn{2}{|l|}{ PMv } \\
\hline & $\overline{\mathrm{HI}}$ & $\mathbf{H} 2$ & $\overline{\mathrm{Hl}}$ & $\mathbf{H} 2$ & $\overline{\text { III }}$ & $\mathrm{H} 2$ \\
\hline C7-T1 neurons & $4610(46 \%)$ & $5619(46 \%)$ & $1306(48 \%)$ & $1998(63 \%)$ & $122(98 \%)$ & $49(100 \%)$ \\
\hline L6-S1 neurons & $5375(54 \%)$ & $6550(54 \%)$ & $1398(52 \%)$ & $1163(37 \%)$ & $1(<1 \%)$ & 0 \\
\hline Double-labeled neurons & $4(<1 \%)$ & $6(<1 \%)$ & $10(<1 \%)$ & $11(<1 \%)$ & $2(2 \%)$ & 0 \\
\hline Total neurons & $9989(100 \%)$ & $12175(100 \%)$ & $2714(100 \%)$ & $3172(100 \%)$ & $125(100 \%)$ & $49(100 \%)$ \\
\hline C7-T1 bins & $1735(45 \%)$ & $2050(48 \%)$ & $493(43 \%)$ & $796(59 \%)$ & $77(99 \%)$ & $31(100 \%)$ \\
\hline L6-S1 bins & $2087(54 \%)$ & $2165(50 \%)$ & $555(49 \%)$ & $508(38 \%)$ & $1(1 \%)$ & 0 \\
\hline Overlap bins & $53(1 \%)$ & $91(2 \%)$ & $90(8 \%)$ & $48(3 \%)$ & 0 & 0 \\
\hline Total bins & $3875(100 \%)$ & $4306(100 \%)$ & $1138(100 \%)$ & $1352(100 \%)$ & $78(100 \%)$ & $31(100 \%)$ \\
\hline C7-T1 neurons in overlap bins & $103(43 \%)$ & $163(43 \%)$ & $170(56 \%)$ & $91(54 \%)$ & 0 & 0 \\
\hline L6-S1 neurons in overlap bins & $135(57 \%)$ & $212(57 \%)$ & $136(44 \%)$ & $78(46 \%)$ & 0 & 0 \\
\hline Total neurons in overlap bins & $238(100 \%)$ & $375(100 \%)$ & $306(100 \%)$ & $169(100 \%)$ & 0 & 0 \\
\hline
\end{tabular}

Neuron counts are based on the data from every fourth section and are not corrected. Neuron counts for each injection site do not include double-labeled neurons. Bin counts for each injection site do not include overlap bins.

corticospinal neurons projecting to lower cervical segments were located as far laterally as those on the gyrus, but extended medially for another $2-4 \mathrm{~mm}$ beyond the level of the SPcS. The number and density of corticospinal neurons declined in the most caudal portion of area 4 (i.e., the lower third of the anterior bank of the CS; Figs. 5, 7). However, rostrally there was no obvious decline in the number of corticospinal neurons at the border between areas 4 and 6 .

A comparison of the distribution of labeled neurons with maps of primary motor cortex generated by surface or intracortical stimulation (e.g., Woolsey et al., 1952; Kwan et al., 1978; Sessle and Wiesendanger, 1982; Kurata, 1989; Sato and Tanji, 1989) suggests that within area 4 , neurons labeled after tracer injections into lower cervical segments were largely confined to the "arm" area of the primary motor cortex and especially to the representations of the fingers and wrist. Only a small number of labeled neurons were found in the "leg" area after tracer injections into lower (or upper) cervical segments. This labeling is most likely due to the slight spread of the injection site into the ventral funiculus where the ventral component of the corticospinal tract travels (for references, see Kuypers, 1981; Davidoff, 1990). No labeled neurons were found in the "face" area of the primary motor cortex.

In contrast, area 4 neurons projecting to lower lumbosacral segments were located in regions of the precentral gyrus that began just medial to the lateral edge of the SPcS [Figs. 5, 6 (sections 331-451), 7]. This group of corticospinal neurons extended medially onto the medial wall of the hemisphere and caudally into the anterior bank of the CS. The labeled neurons in the CS were confined to the upper two-thirds to one-half of its anterior bank. In the region of the anterior bank where neurons labeled after transport from lower lumbosacral segments bordered those labeled after transport from lower cervical segments, neurons projecting to lower lumbosacral segments were located just above those projecting to lower cervical segments.

Few "double-labeled" neurons (Fig. $1 E$ ) were found in any cortical area of $\mathrm{H} 1$ and $\mathrm{H} 2$ (Table 2). Indeed, such neurons represented only $0.2 \%$ of the total sample of labeled neurons. The small number of double-labeled neurons found in area 4 were primarily located in regions of the precentral gyrus where neurons projecting to lower lumbosacral segments abutted those projecting to lower cervical segments. Because of their small number, the locations of double-labcled ncurons are not displayed on the surface maps.

In general, the neurons in area 4 that were labeled after transport from lumbosacral segments were located largely within the "leg" area of the primary motor cortex (e.g., Woolsey et al., 1952; Tanji and Wise, 1981; Wise and Tanji, 1981; Kurata, 1989). No labeled neurons were found in the face area. In animals with tracer injections into lower lumbosacral segments, few, if any, labeled neurons were found in the "arm" area of the primary motor cortex. For example, in $\mathrm{H} 1$ and $\mathrm{H} 2$, less than $0.4 \%$ of the neurons in area 4 that projected to lower lumbosacral segments were found in the region of area 4 that projected to lower cervical segments ( $\mathrm{H} 1,16$ out of 5375 labeled neurons; H2, 24 out of 6550 labeled neurons). Thus, within area 4 , the population of corticospinal neurons projecting to lower lumbosacral segments was almost entirely separate from that projecting to lower cervical segments. On the other hand, in the animal with tracer placed into the dorsolateral funiculus at $\mathrm{T} 7$ (K3), a few small patches of labeled neurons were found within regions of area 4 that extend beyond the lateral edge of the SPCS (Fig. 8B). Most physiological maps include this region of area 4 within the medial part of the arm representation (Woolsey et al., 1952; Kwan et al., 1978; Sessle and Wiesendanger, 1982). This finding suggests that there is some overlap between the population of corticospinal neurons projecting to mid-thoracic segments and that projecting to cervical segments.

Figure 7. Density of corticospinal neurons projecting to lower cervical and lower lumbosacral segments in animal $\mathrm{H} 2 . A$, The density of neurons projecting to lower lumbosacral segments. $B$, The density of neurons projecting to lower cervical segments. The procedures used for dividing cortex into bins ( $200 \mu \mathrm{m}$ on a side) and for correcting density counts for the angulation of the CS are described in Materials and Methods. The key at the lower right indicates the color coding for the number of labeled neurons in each bin. White, yellow, and red bins represent approximately the upper $20 \%$ of the total sample of bins (i.e., "high-density bins"). Bins containing only one cell are not displayed in this and the other density maps. See Figure 4 for details. 
K3 (HRP, T7)
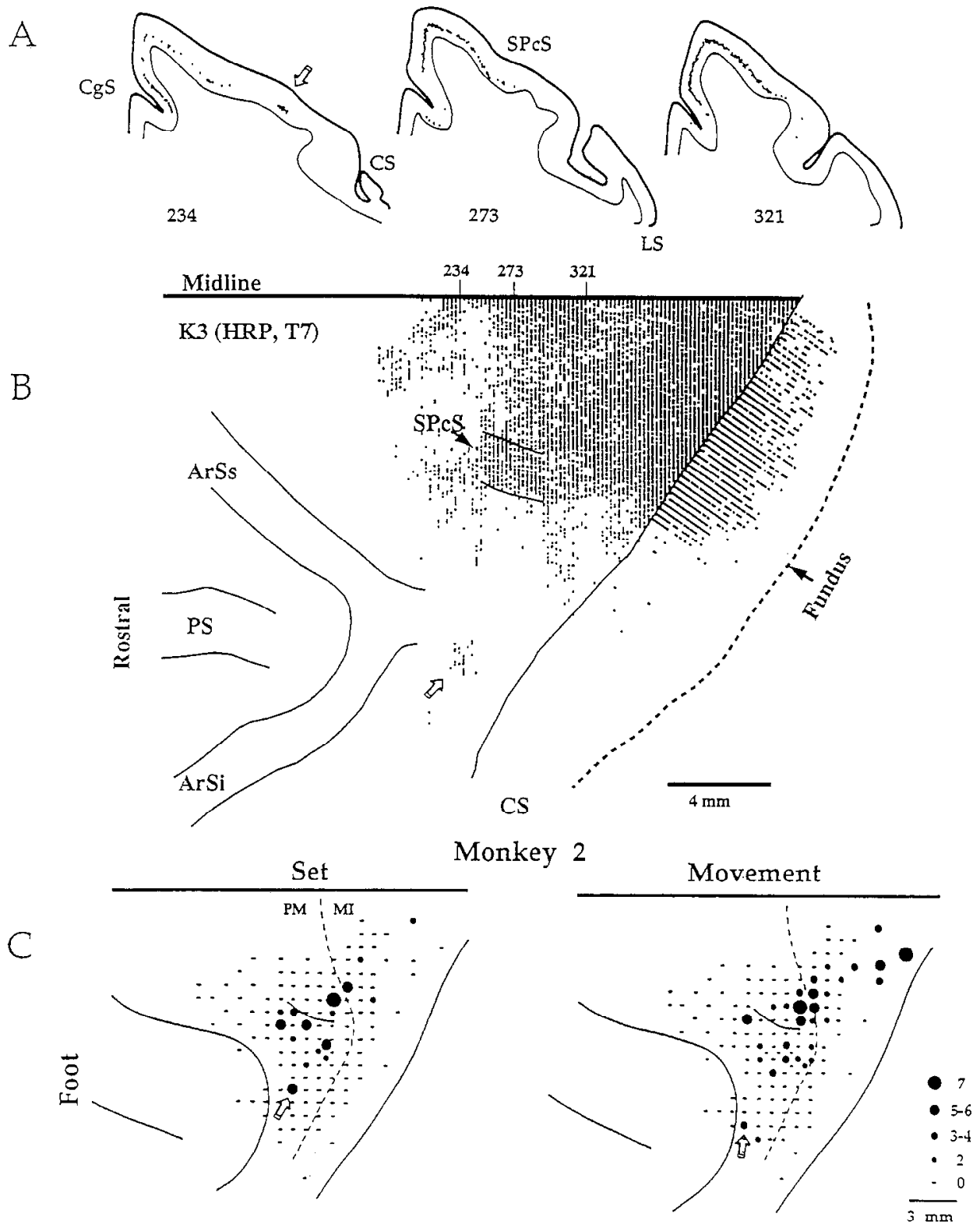

Figure 8. Comparison of anatomical and physiological data defining areas of hindlimb representation. $A$, Plots of labeled neurons on coronal sections from animal K3. The level of each section is indicated by the number below each diagram. The location of each section is indicated by the numbered lines in $B$. The open arrow over section 234 points to a small isolated cluster of neurons located just caudal and lateral to the spur of the ArS. $C g S$, cingulate sulcus. $B$, The distribution of neurons labeled in animal $\mathrm{K} 3$ following the placement of HRP into the dorsolateral funiculus at T7. The open arrow indicates the location of the small patch of labeled neurons that is just caudal and lateral to the spur of the ArS. See Figures 4 and 5 for conventions and abbreviations. $C$, The distribution of neurons displaying set-related (left $)$ and movement-related (right) activity during the performance of a motor task involving simple movements of the foot (adapted from Kurata, 1989). The size of the solid circles indicatcs the number of related neurons at each site (see key at lower right). The open arrows indicate the location of a small isolated group of single neurons that displayed set- and/or movementrelated activity specifically during the foot motor task. The broken line indicates the area $4 / 6$ border. $M I$, primary motor cortex; $P M$, premotor cortex.

$P M v$. Only a small number of labeled neurons were found in the PMv after tracer injections into lower cervical segments (Figs. 5-7; see also Table 2). This result contrasts with the moderate density of labeled neurons seen in this cortical area after tracer injections that involved upper segments of cervical cord (Table 3; see also Martino and Strick, 1987; Dum and Strick, $1989,1991 \mathrm{~b})$. Only three labeled neurons were found in the PMv after tracer injections into lower lumbosacral segments (Table 2). However, when HRP was placed in the dorsolateral funiculus at T7 (K3), a small isolated patch of labeled neurons was found in a region of the PMv that is caudal to the inferior limb of the ArS and just lateral to its spur [see open arrows in Fig. $8 A$ (section 234), $B$ ]. The location of these labeled neurons (open arrow in Fig. 8B) appears to correspond to the cortical region where Kurata (1989) found an isolated group of neurons in awake monkeys (open arrow in Fig. 8C) that showed changes in activity specifically related to foot but not hand movements (compare Fig. $8 B, C$ ). Neurons in this region changed their activity during the period just before the actual movement (movement-related; Fig. $8 C$, right) and/or during the period when the animal was preparing to make a foot movement (set-related; Fig. $8 C$, left).

$P M d$. After tracer injections into lower cervical and lower lumbosacral segments, a considerably larger number of corticospinal neurons was found in the PMd than in the PMv (Table 2). For example, in $\mathrm{H} 1$, a total of 2714 labeled neurons were located in the PMd and only 125 labeled neurons were found in the PMv. By comparison, 9989 labeled neurons were found in area 4 in $\mathrm{H} 1$. In some animals, the regions of the PMd with dense projections to lower cervical segments were separate from those in area 4 (e.g., H2, Fig. 7B; H7, Fig. 13B), but this was not always the case (e.g., H3, Fig. 12B).

Corticospinal neurons projecting to cervical or lumbosacral segments of the spinal cord were located in largely separate 

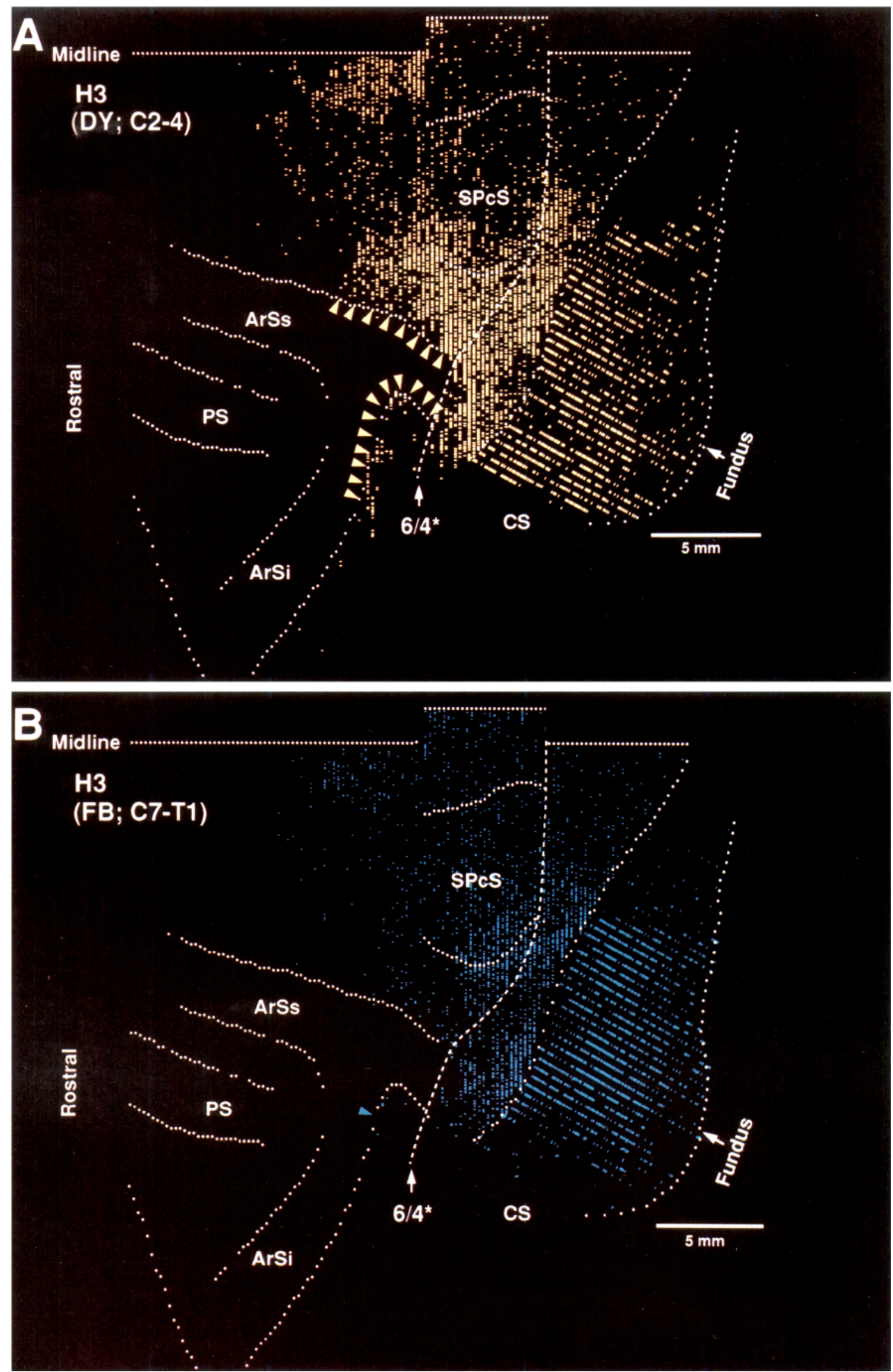

Figure 9. Maps of corticospinal neurons projecting to cervical segments in animal $\mathrm{H} 3$. $A$, The distribution of neurons in animal $\mathrm{H} 3$ that were labeled by tracer injections into upper cervical segments $(\mathrm{C} 2-\mathrm{C} 4) . B$, The distribution of neurons in animal $\mathrm{H} 3$ that were labeled by tracer injections into lower cervical segments (C7-T1). Solid arrowheads indicate the location of labeled neurons in the inferior limb (ArSi) and spur of the ArS. The SPcS has been unfolded medially in this map and following maps. See Figures 4 and 5 for conventions and further abbreviations. 


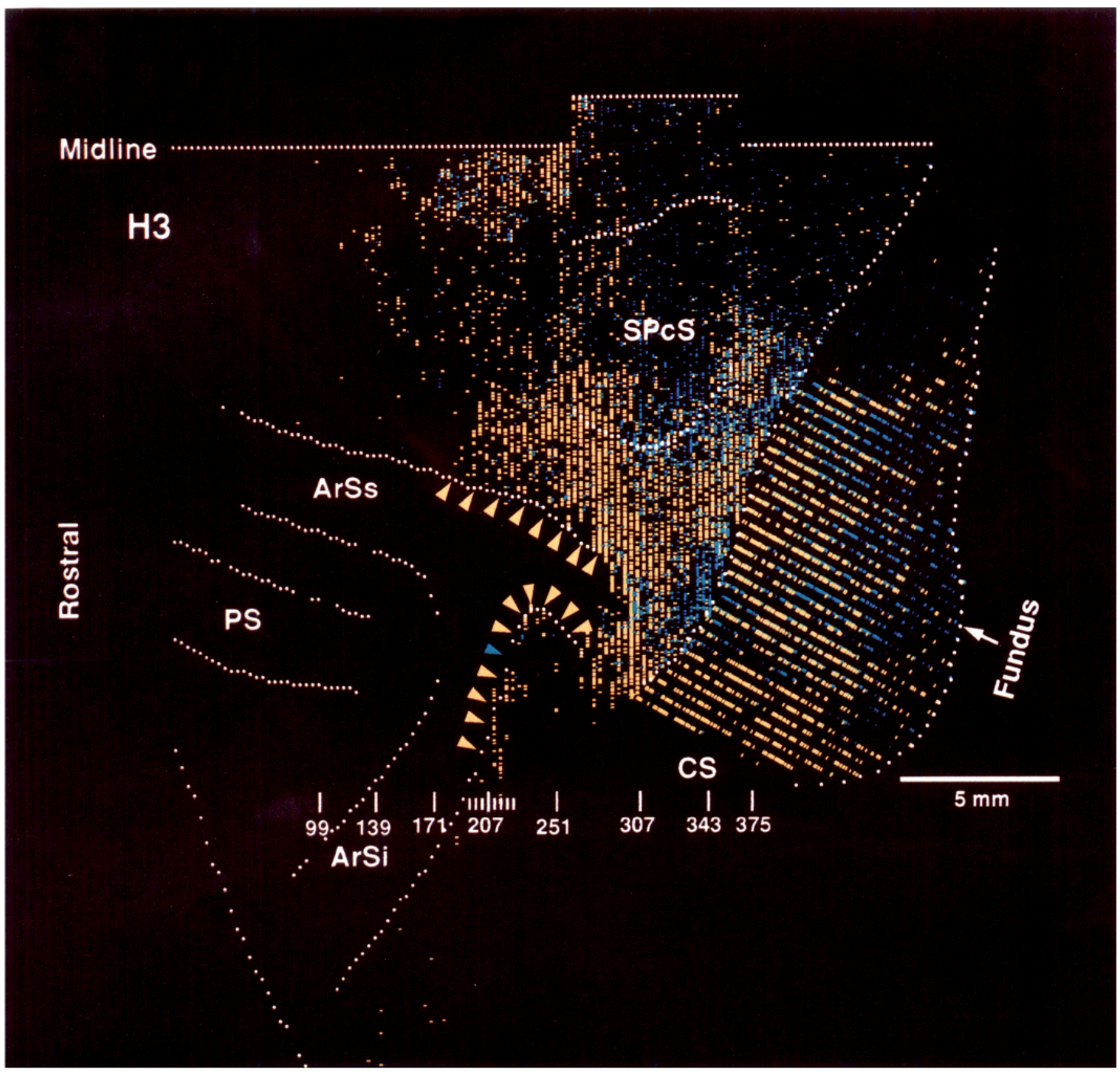

Figure 10. Combined map of corticospinal neurons in $\mathrm{H} 3$ projecting to upper and lower cervical segments. Yellow dots, neurons projecting to upper cervical segments (C2-C4); blue dots, neurons projecting to lower cervical segments (C7-T1). See Figures 4, 5, and 9 for details.

regions of the PMd [Figs. 5, 6 (sections 295-375), 7]. Most of the neurons projecting to lower cervical segments were located in and around the lateral edge of the SPcS (Figs. 5, 7B; see also Figs. $12 \mathrm{~B}, 13 \mathrm{~B}$ ). In contrast, most of the neurons projecting to lower lumbosacral segments were located more medially, in and around the medial edge of the SPcS (Figs. 5, 7A). However, two additional small clusters of corticospinal neurons were located within the SPcS. One of these, located rostrolaterally in the sulcus, projected to lumbosacral segments and the other, located more caudomedially, projected to cervical segments (Fig. 5).

The region of the PMd that is lateral to the SPcS and projects to lower cervical segments appears to correspond to an area that is interconnected with the "hand" representation of the primary motor cortex (e.g., Muakkassa and Strick, 1979; Godschalk et al., 1984; Strick, 1985). This area also appears to correspond to the region where Kurata (1989) found large numbers of neurons displaying set-and/or movement-related changes in activity during hand movements. The same anatomical and physiological studies provide support for a "foot" representation in the region of the PMd that is medial to the SPcS and projects to lower lumbosacral segments. There have been no recent attempts to map motor representation of cortex buried in the SPcS, and thus there are no data concerning the body parts represented at the small sites there that project to cervical and lumbosacral segments. 

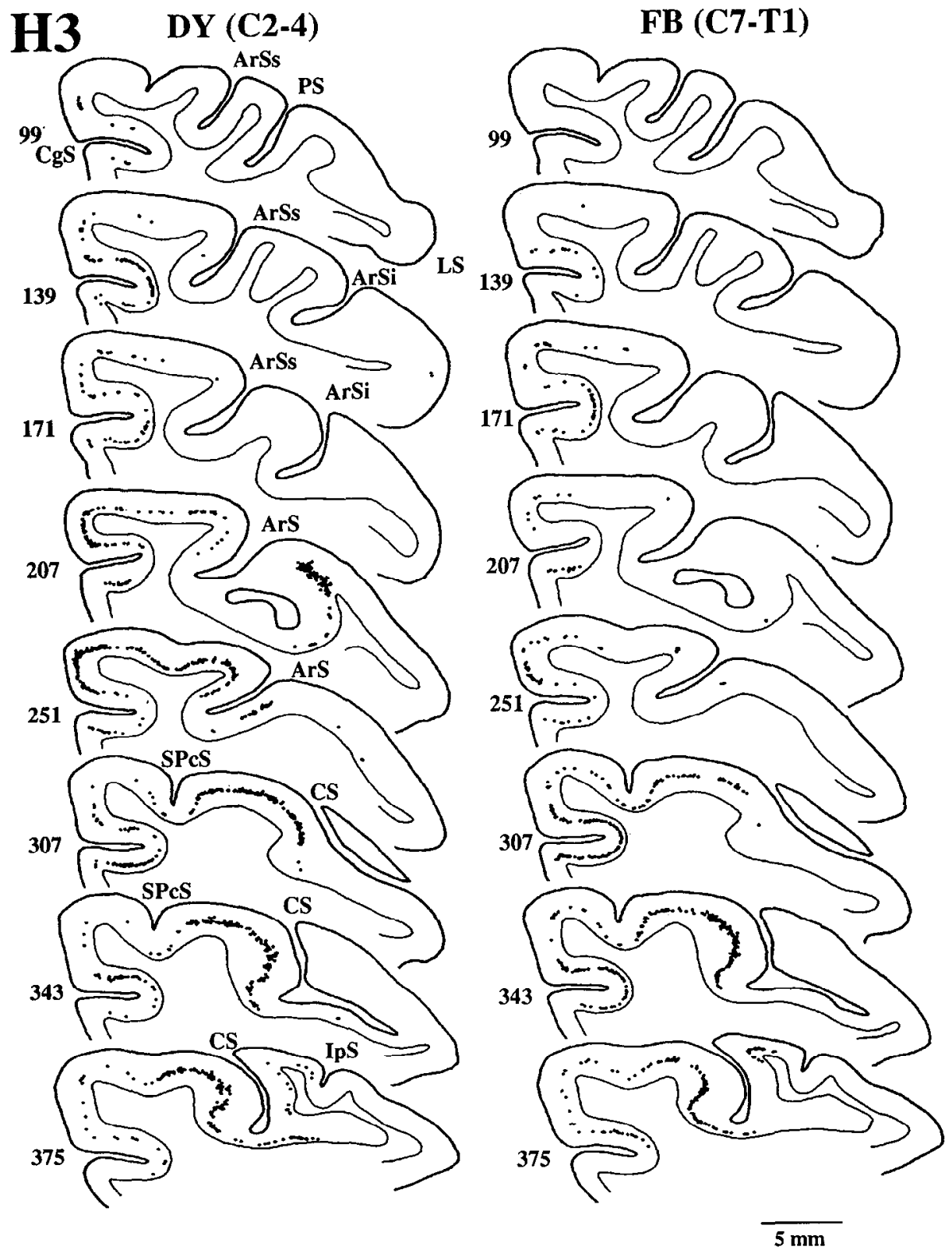

Figure 11. Plots of labeled neurons in animal $\mathrm{H} 3$. The level of each coronal section is indicated by the number to the left of each diagram. The location of each section in the frontal lobe is indicated by the numbered lines in Figure 10. In this animal, FB was injected into lower cervical segments (C7-T1) and DY was injected into upper cervical segments (C2-C4). The injection sites are illustrated in Figure 3. See Figures 4 and 6 for details.

\section{Comparison of corticospinal projections to upper cervical and lower cervical segments}

Primary motor cortex. We found considerable overlap in the regions of area 4 that projected to upper cervical segments and the regions that projected to lower cervical segments (Figs. 911). To examine quantitatively the extent of overlap in the cortical regions containing FB- and DY-labeled neurons, we divided the frontal cortex into bins $200 \mu \mathrm{m}$ on a side. We then determined the number of bins containing (1) only neurons labeled with FB, (2) only neurons labeled with DY, and (3) both types of labeled neurons (termed "overlap" bins). In animals with tracer injections into upper and lower cervical segments, approximately $28 \%$ of the bins in area 4 were overlap bins (Table 3 ). In contrast, overlap bins represented only $1-2 \%$ of the total bins in area 4 of animals that received tracer injections into lower cervical and lower lumbosacral segments $(\mathrm{H} 2,2 \% ; \mathrm{H} 1$, $1 \%$; see Table 2).
Despite this overlap, the regions of area 4 that projected most densely to lower cervical segments were surprisingly separate from those that projected most densely to upper cervical segments (Figs. 12-14). We determined the density of corticospinal neurons by counting the number of labeled neurons in each 200 $\mu \mathrm{m}$ bin. Bins with a density in the upper $20 \%$ of the total sample were defined as "high-density" bins (i.e., the white-, yellow-, and red-colored bins in our density maps). These bins contained approximately $45-50 \%$ of the total number of corticospinal neurons labeled by tracer injections into any segmental level. We found that there was little overlap of the high-density bins containing neurons that innervate lower cervical segments with those containing neurons that innervate upper cervical segments $(\mathrm{H} 3,3 \% ; \mathrm{H} 7,10 \%)$. In total, the area of cortex containing highdensity bins with neurons that innervate lower cervical segments was approximately equal to that containing high-density bins that innervate upper cervical segments (Table 4).

Within area 4 , most of the high-density bins with corticospinal 
Table 3. Distribution of corticospinal neurons projecting to upper cervical (C2-C4) and lower cervical (C7-T1) segments

\begin{tabular}{|c|c|c|c|c|c|c|}
\hline & \multicolumn{2}{|l|}{ M1 } & \multicolumn{2}{|l|}{ PMd } & \multicolumn{2}{|l|}{ PMv } \\
\hline & H3 & $\mathrm{H} 7$ & H3 & H7 & H3 & H7 \\
\hline $\mathrm{C} 2-\mathrm{C} 4$ neurons & $3048(57 \%)$ & $1743(34 \%)$ & $2397(66 \%)$ & $973(39 \%)$ & $776(92 \%)$ & $358(78 \%)$ \\
\hline C7-T1 neurons & $2100(39 \%)$ & $3171(62 \%)$ & $1044(29 \%)$ & $1475(59 \%)$ & $56(7 \%)$ & $92(20 \%)$ \\
\hline Double-labeled neurons & $208(4 \%)$ & $200(4 \%)$ & $189(5 \%)$ & $48(2 \%)$ & $9(1 \%)$ & $9(2 \%)$ \\
\hline Total neurons & $5356(100 \%)$ & $5114(100 \%)$ & $3630(100 \%)$ & $2496(100 \%)$ & $841(100 \%)$ & $459(100 \%)$ \\
\hline $\mathrm{C} 2-\mathrm{C} 4$ bins & $995(39 \%)$ & $536(22 \%)$ & $968(53 \%)$ & $420(31 \%)$ & $351(87 \%)$ & $160(72 \%)$ \\
\hline C7-T1 bins & $850(33 \%)$ & $1163(49 \%)$ & $620(34 \%)$ & $795(58 \%)$ & $31(8 \%)$ & $37(17 \%)$ \\
\hline Overlap bins & $731(28 \%)$ & $689(29 \%)$ & $231(13 \%)$ & $150(11 \%)$ & $23(5 \%)$ & $26(11 \%)$ \\
\hline Total bins & $2576(100 \%)$ & $2388(100 \%)$ & $1819(100 \%)$ & $1365(100 \%)$ & $405(100 \%)$ & $223(100 \%)$ \\
\hline $\mathrm{C} 2-\mathrm{C} 4$ neurons in overlap bins & $1336(52 \%)$ & $918(43 \%)$ & $556(59 \%)$ & $270(52 \%)$ & $49(62 \%)$ & $51(49 \%)$ \\
\hline C7-T1 neurons in overlap bins & $1236(48 \%)$ & $1233(57 \%)$ & $383(41 \%)$ & $250(48 \%)$ & $30(38 \%)$ & $54(51 \%)$ \\
\hline Total neurons in overlap bins & $2572(100 \%)$ & $2151(100 \%)$ & $939(100 \%)$ & $520(100 \%)$ & $79(100 \%)$ & $105(100 \%)$ \\
\hline
\end{tabular}

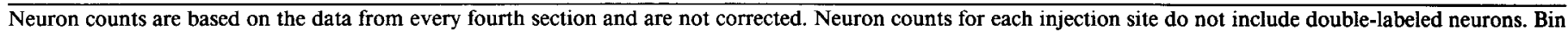
counts for each injection site do not include overlap bins.

neurons that project to upper cervical segments formed a single, large peak shaped like a "crescent" (Figs. 12A, 13A, 14). We will designate this peak of labeled neurons the lateral upper cervical peak (UC peak). The rostral edge of the lateral UC peak was located on the precentral gyrus along the area $4 / 6$ border (Fig. 14). The medial and lateral ends of the lateral UC peak extended into the anterior bank of the CS (see also Dum and Strick, 1989, their Fig. 2). A second, much smaller group of high-density bins with neurons that project to upper cervical segments was located immediately caudal to the SPcS at the level of its lateral edge (Figs. $12 A, 13 A, 14$ ). This second peak of labeled neurons will be termed the medial UC peak. The area of cortex occupied by the medial UC peak was less than a 10th of the area of the lateral UC peak (Table 5).

The high-density bins of area 4 neurons that innervate lower cervical segments also formed two peaks (Figs. $12 B, 13 B, 14$; see also Fig. $7 B$ ). Each peak consisted of rostrocaudally oriented bands that began on the crest of the precentral gyrus and extended well into the anterior bank of the CS. One of the peaks filled the concavity of the crescent formed by the lateral UC, peak and will be termed the lateral lower cervical peak (lateral LC peak; Fig. 14). The second peak was located more medially and was aligned with the lateral edge of the SPcS. This peak will be termed the medial LC peak. In two of the animals we have illustrated [H2 (Fig. $7 B$ ) and $\mathrm{H} 3$ (Fig. 12B)], there was a clear low-density valley between the two LC peaks. In animal $\mathrm{H} 3$, this valley was filled with neurons that projected to upper cervical segments (i.e., the medial end of the lateral UC peak; Fig. 14A). In the third animal illustrated $(\mathrm{H} 7)$, the two LC peaks were clearly separate in the CS, but appeared to be connected along the caudal edge of the precentral gyrus (Fig. 13B). However, the two peaks were bisected by the medial extension of the UC peak (Fig. 13A). Thus, in animal H7, there was a region between the two LC peaks that did not project exclusively to lower cervical segments (note the red bins in Fig. $14 \mathrm{~B}$ that indicate overlap bins). Consequently, in all three of the animals illustrated, there is evidence for two spatially separate regions in the primary motor cortex with corticospinal output directed primarily to lower cervical segments.

The two LC peaks were quite comparable in terms of their size and the number of corticospinal neurons they contained (Table 5). Nineteen to twenty percent of the area 4 neurons that innervate lower cervical segments were located in the medial LC peak, and $17-21 \%$ of the neurons were located in the lateral LC peak. Furthermore, the area of cortex occupied by the medial LC peak was $83-86 \%$ as large as that of the lateral LC peak.

\section{Table 4. Size of high-density "peaks" in the primary motor cortex and the premotor areas of the lateral hemisphere}

\begin{tabular}{|c|c|c|c|c|c|c|}
\hline & \multicolumn{2}{|l|}{ M1 } & \multicolumn{2}{|l|}{ PMd } & \multicolumn{2}{|l|}{ PMv } \\
\hline & $\overline{\mathrm{H} 3}$ & H7 & $\mathrm{H} 3$ & $\mathbf{H} 7$ & $\overline{\mathrm{H} 3}$ & H7 \\
\hline Area of UC peaks & $40.3(50 \%)$ & $36.9(49 \%)$ & $23.5(62 \%)$ & $25.7(62 \%)$ & $17.7(97 \%)$ & $16.7(87 \%)$ \\
\hline Area of LC peaks & $40.2(50 \%)$ & $38.7(51 \%)$ & $14.5(38 \%)$ & $16(38 \%)$ & $0.5(3 \%)$ & $2.4(13 \%)$ \\
\hline Total & $80.5(100 \%)$ & $75.6(100 \%)$ & $38(100 \%)$ & $41.7(100 \%)$ & $18.2(100 \%)$ & $19.1(100 \%)$ \\
\hline Bins in UC peaks (neuron counts) & $201(1215)$ & $233(702)$ & $181(1002)$ & $142(419)$ & $52(293)$ & $61(163)$ \\
\hline Bins in LC peaks (neuron counts) & $226(880)$ & $275(1136)$ & $62(227)$ & $92(342)$ & $1(3)$ & $7(28)$ \\
\hline Overlap of bins (neuron counts) & $14(68)$ & $59(213)$ & $7(35)$ & $16(70)$ & 0 & $5(14)$ \\
\hline Total bins (neuron counts) & $441(2163)$ & $567(2051)$ & $250(1264)$ & $250(831)$ & $53(296)$ & $73(205)$ \\
\hline
\end{tabular}

The measurements represent the surface area ( $\left.\mathrm{mm}^{2}\right)$ of the high-density "peaks." UC peaks, upper cervical peaks (C2-C4); LC peaks, lower cervical peaks (C7-T1). Area of UC peaks in M1 = medial + lateral UC peak; area of LC peaks in M1 = medial + lateral LC peak.

${ }^{a}$ High-density "peaks" are the high-density bins that represent approximately the upper $20 \%$ of the total sample of bins (i.e., the white, yellow and red bins in the density maps). 

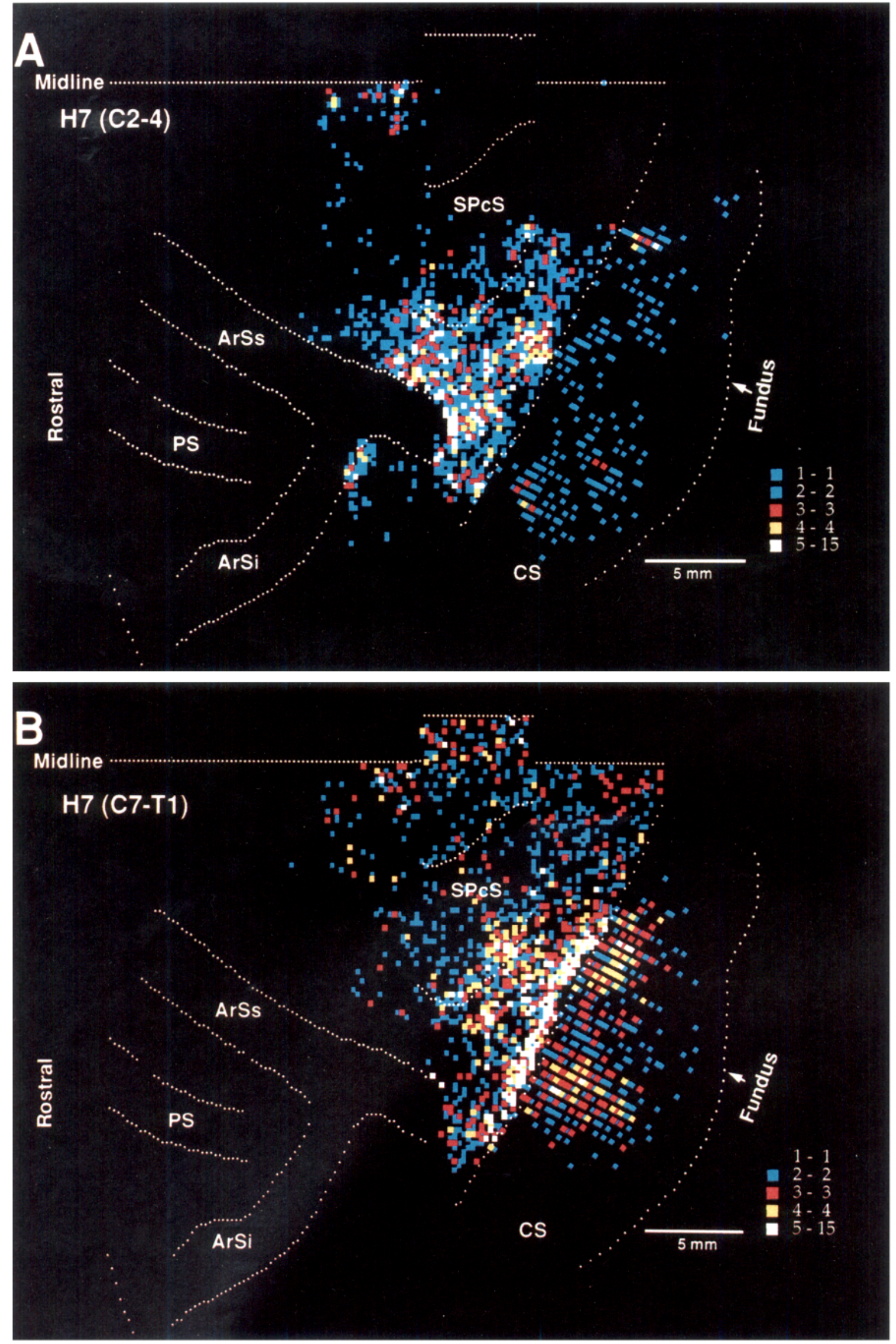

Figure 13. Density of corticospinal neurons projecting to lower and upper cervical segments in animal H7. A, The density of neurons projecting to upper cervical segments $(\mathrm{C} 2-\mathrm{C} 4)$. B. The density of neurons projecting to lower cervical segments $(\mathrm{C} 7-\mathrm{T} 1)$. The key at the lower right indicates the color coding for the number of labeled neurons in each bin. See Figures 4 and 7 for details. 

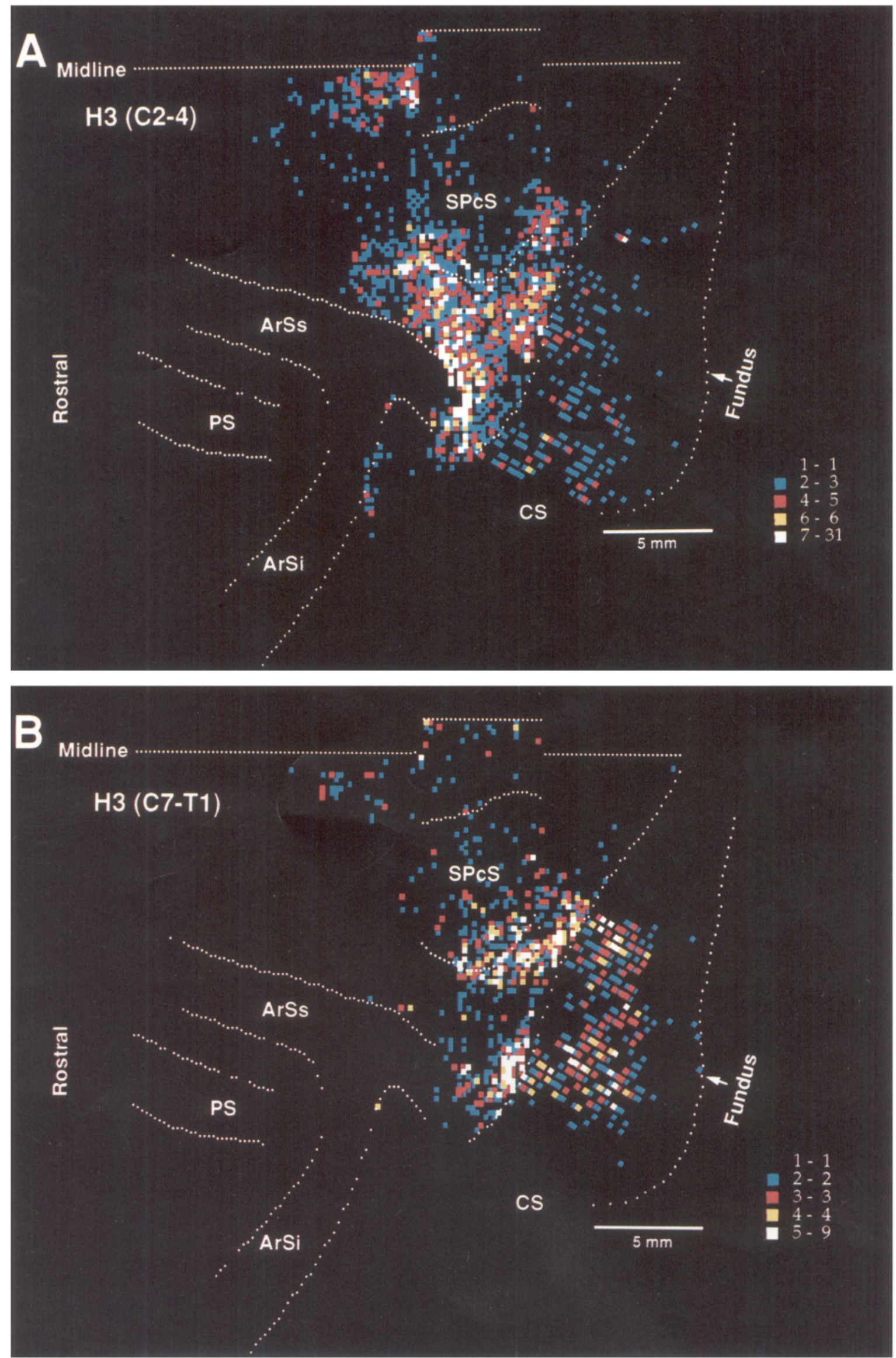

Figure 12. Density of corticospinal neurons projecting to lower and upper cervical segments in animal $\mathrm{H} 3$. $A$, The density of neurons projecting to upper cervical segments $(\mathrm{C} 2-\mathrm{C} 4)$. B. The density of neurons projecting to lower cervical segments $(\mathrm{C} 7-\mathrm{T} 1)$. The key at the lower right indicates the color coding for the number of labeled neurons in each bin. See Figures 4 and 7 for details. 
Table 5. Size of the medial and lateral "peaks" in the primary motor cortex

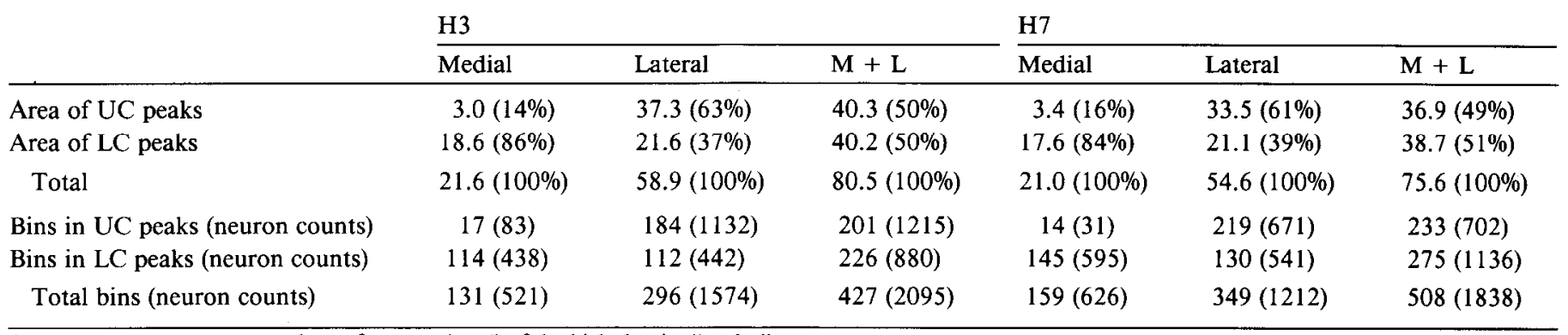

Area measurements represent the surface area $\left(\mathrm{mm}^{2}\right)$ of the high-density "peaks."

A small number of double-labeled neurons were found in area 4 after tracer injections into upper and lower cervical segments (e.g, in H3, 208 of 5356 labeled neurons in area 4; see Table 3). Most of these neurons were located on the precentral gyrus and only a few were found in the CS (Fig. 15). Only 13-18\% of the double-labeled neurons were found in bins that contained a high-density of neurons projecting to lower cervical segments (Fig. 15). Thus, double-labeled neurons were largely located in regions of area 4 that project to upper cervical segments.

The location of the lateral UC peak is very similar to the region of the primary motor cortex where intracortical stimulation evokes shoulder and elbow movements (e.g., the "nested ring" of Kwan et al., 1978; see also Sessle and Wiesendanger, 1982). Similarly, the location of the lateral LC peak is comparable to the region of the primary motor cortex where intracortical stimulation evokes finger and wrist movements (e.g., the "core" of Kwan et al., 1978; see also Sessle and Wiesendanger, 1982; Sato and Tanji, 1989). On the other hand, the medial LC peak and the even more medial, small UC peak were located in a region of the primary motor cortex that lies at the border between the fore- and hindlimb representations as defined by stimulation of the cortical surface. (Woolsey et al., 1952). This region of the primary motor cortex has not been mapped extensively in recent studies.

$P M v$. Compared to the arm area of the primary motor cortex, a relatively small percentage of the corticospinal projection to the cervical cord originates from the PMv. For example, in $\mathrm{H} 3$, tracer injections into upper cervical segments labeled approximately four times the number of neurons in the primary motor cortex as in the PMv (3048 vs 776; see Table 3 ). However, since the area of the PMv is considerably smaller than the primary motor cortex (Table 4), the actual density of corticospinal neurons in the PMv approaches that in the primary motor cortex (Dum and Strick, 1991b).

As noted above, we found that few corticospinal neurons in the PMv were labeled by tracer injections into lower cervical segments (Fig. 16). In fact, in $\mathrm{H} 3$ and $\mathrm{H} 7$, between $78 \%$ and $92 \%$ of the PMv neurons that projected to cervical segments of the spinal cord were labeled only by the injections into upper cervical segments (Table 3; see also Fig. 16). In addition, very few double-labeled neurons were found in the PMv (e.g., in H3, 9 out of 841 labeled neurons; see Table 3). These results confirm our earlier observations that the corticospinal projection from the PMv is focused largely upon upper cervical segments (Martino and Strick, 1987; Dum and Strick, 1989, 1991b).

Confirming our prior studies, corticospinal neurons in the PMv were located largely in the caudal bank of the ArS along its inferior limb (see arrowheads in Figs. 9, 10, 14). Some labeled neurons also were found on the cortical surface in regions that were adjacent to the inferior limb and lateral to the spur of the ArS (Figs. 9, 10). The few neurons in the PMv that projected to lower cervical segments appeared to be intermingled with those that project to upper cervical segments. The region of the PMv that contained neurons that project to cervical segments of the spinal cord appears to correspond to the "arm" area of the PMv described in prior anatomical (e.g., Matsumura and Kubota, 1979; Muakkassa and Strick, 1979; Godschalk et al., 1984) and physiological studies (e.g., Godschalk et al., 1981, 1985; Rizzolatti et al., 198 1a, 1988; Kurata et al., 1985; Kurata and Tanji, 1986; Gentilucci et al., 1988, 1989; Kurata, 1989).

$P M d$. Compared to the PMv, a larger pcrcentage of the corticospinal system originates from the PMd. For example, in H3, tracer injections into upper cervical segments labeled approximately three times the number of neurons in the PMd as in the PMv (2397 vs 776; see Table 3). In fact, the total number of labeled neurons in the PMd of $\mathrm{H} 3$ after lower and upper cervical injections of tracer was almost two-thirds the number found in the primary motor cortex (3630 vs 5356; see Table 3 ). Thus, even though the PMd is about half the size of the primary motor cortex (Table 4), it is clear that a substantial component of the corticospinal projection to cervical segments originates from the PMd.

In the PMd, like in the primary motor cortex, neurons that project to lower cervical segments were intermingled with neurons that project to upper cervical segments (Figs. 9, 10). However, only $11-13 \%$ of the total sample of bins in the PMd were "overlap bins" (i.e., bins with neurons projecting to upper ccrvical segments and neurons projecting to lower cervical segments). Thus, the amount of intermingling in the PMd appeared to be somewhat smaller than that observed in the primary motor cortex (28-29\%).

Our analysis of corticospinal neuron density revealed that projections to different cervical segments were concentrated in distinct regions of the PMd (Figs. 12-14). Neurons in the PMd that project to lower cervical segments were most dense in cortical regions in and around the lateral bank of the $\mathrm{SPCS}$, particularly the caudal two-thirds of this sulcus (Figs. 12B, 13B, 14). On the other hand, neurons that project to upper cervical segments were concentrated in more rostral and lateral regions of the PMd (Figs. 12A, 13A, 14; see also Fig. 11, section 251). Only $2.8-6.4 \%$ of the high-density bins in the PMd that project to lower cervical segments overlapped the high-density bins with neurons that project to upper cervical segments. Thus, within the PMd, the peak density of corticospinal neurons that project to lower cervical segments was largely separate from the peak density of neurons that project to upper cervical segments (Fig. 

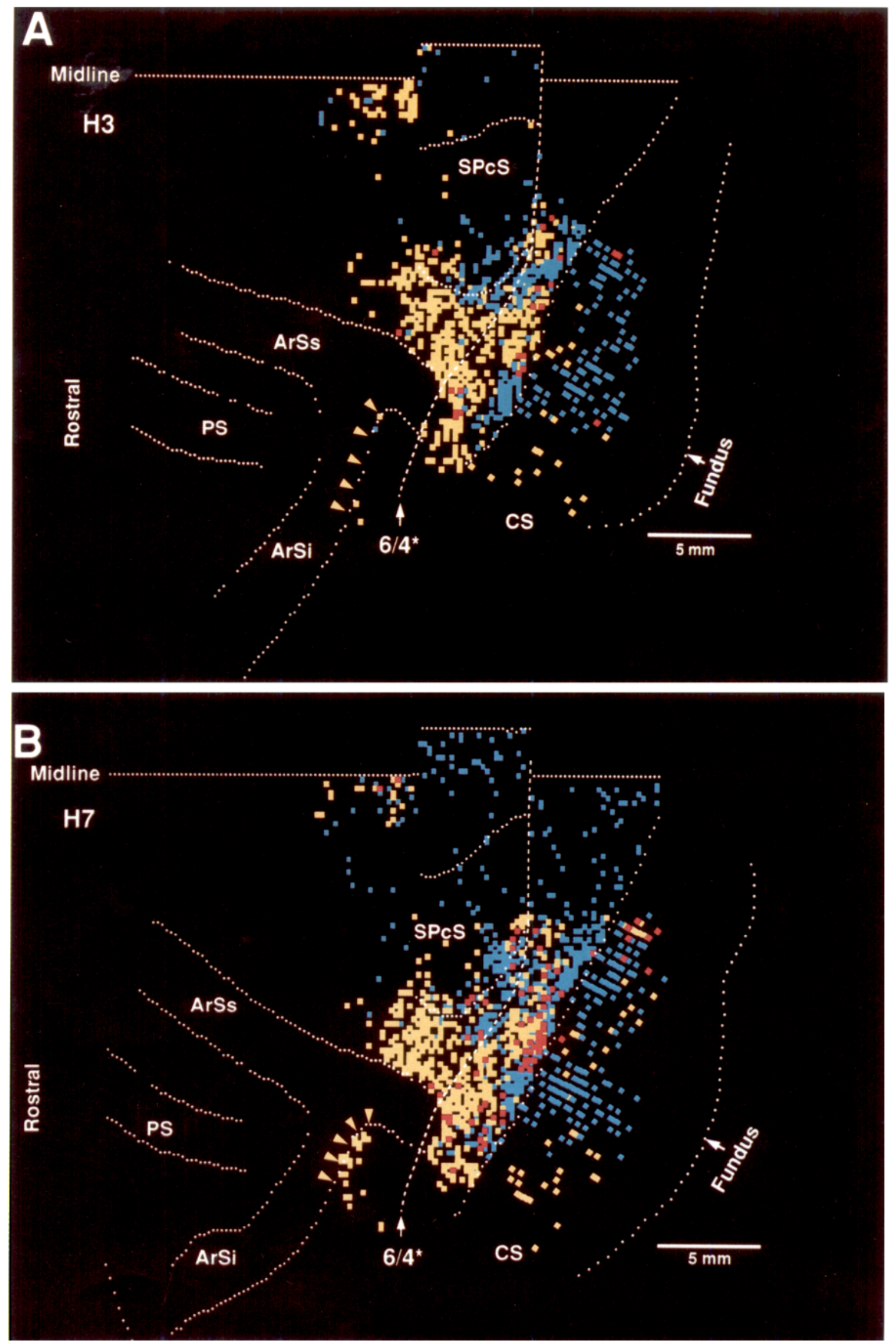


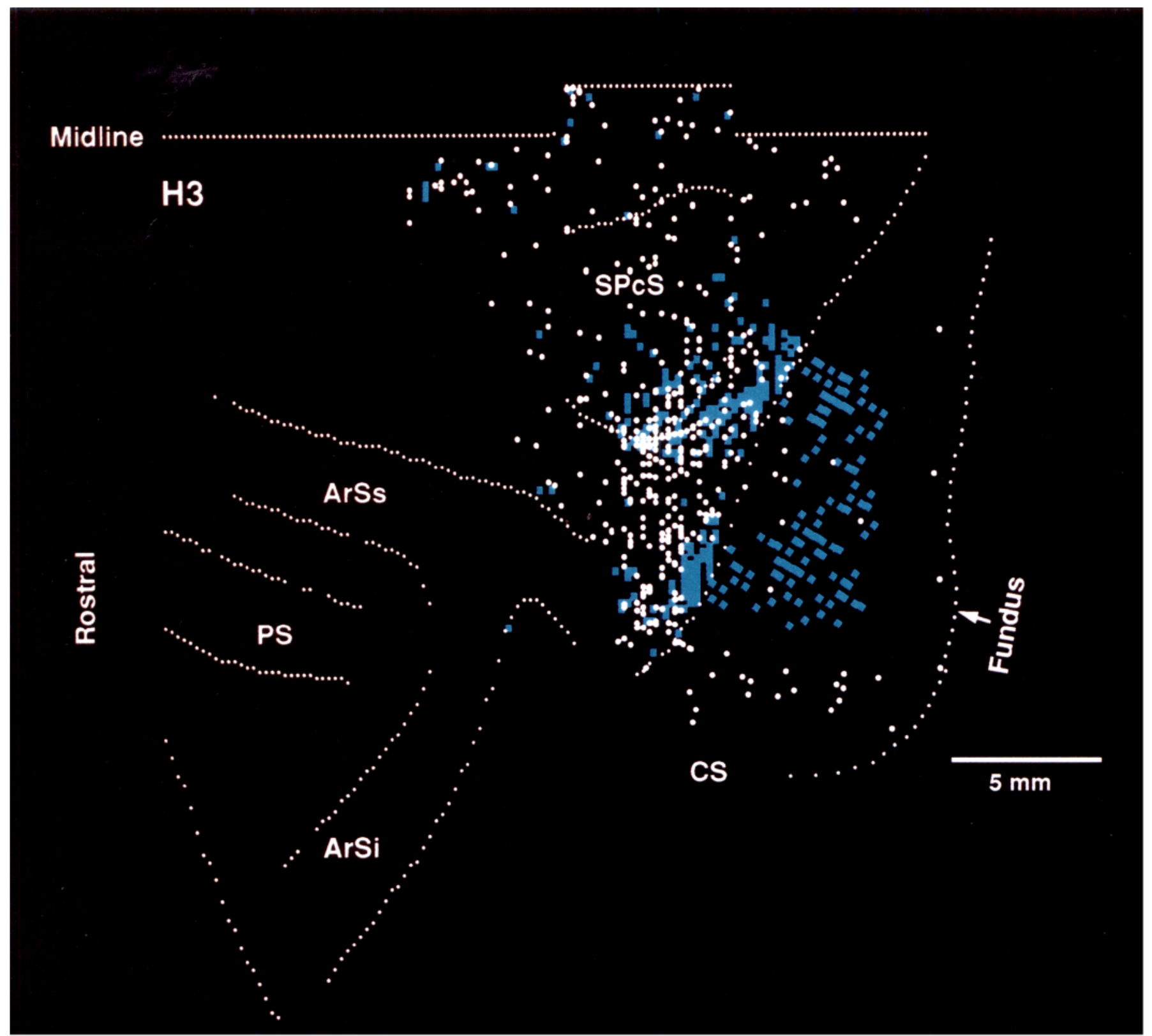

Figure 15. Map of "double-labeled" neurons in H3. Each white circle indicates the location of a neuron labeled with the tracer that was injected into lower cervical segments and with the tracer that was injected into upper cervical segments (see, e.g., Fig. $1 E$ ). The blue rectangles represent bins that contain a high density of neurons labeled with the tracer that was injected into lower cervical segments. Note that most of the doublelabeled neurons did not overlap the medial and lateral LC peaks in area 4. See Figures 4 and 9 for details.

14). When these findings are compared with the results from a similar analysis of area 4 (see above), it is clear that the origin of corticospinal projections from the PMd to different cervical segments is as topographically organized as that from the primary motor cortex.

A relatively larger amount of cortex within the PMd was allotted to corticospinal projections to upper cervical segments than was allotted to projections to lower cervical segments (Table 4). For example, the ratio of the area of the PMd projecting most densely to upper cervical segments versus that projecting most densely to lower cervical segments was approximately 1.62:1 in $\mathrm{H} 3$ and 1.6:1 in $\mathrm{H} 7$. In contrast, approximately equal

Figure 14. Combined maps of high-density "peaks" of corticospinal neurons projecting to upper cervical or lower cervical segments. The highdensity "peaks" represent approximately the upper $20 \%$ of the total sample of bins. These are the white-, yellow-, and red-colored bins in Figures 12 and 13. In this figure bins are colored blue when they contain a high density of neurons labeled with tracer from the injection into lower segments, yellow when they contain a high density of neurons labeled with tracer from the injection into upper cervical segments, and red when the blue and yellow bins overlap. A, High-density "peaks" in animal H3 (compare with Fig. 12A,B). B, High-density "peaks" in animal H7 (compare with Fig. $13 A, B)$. Note (1) the similarity in the topographic distribution of high-density "peaks" in $\mathrm{H} 3$ and $\mathrm{H} 7,(2)$ that two spatially separate LC peaks exist within area 4, and (3) that LC and UC peaks are found in the PMd. See Figures 4 and 9 for details. 
Figure 16. Plots of labeled neurons in $\Lambda \mathrm{rS}$ of animal H3. The level of each coronal section is indicated by the numbers to the left of each diagram. The location of each section in the frontal lobe is indicated by the short lines adjacent to section 207 in Figure 10. Note that large numbers of labeled neurons are found in the ArS, particularly the caudal bank of its inferior limb, only after tracer injections into upper cervical segments. See Figures 4 and 6 for abbreviations.

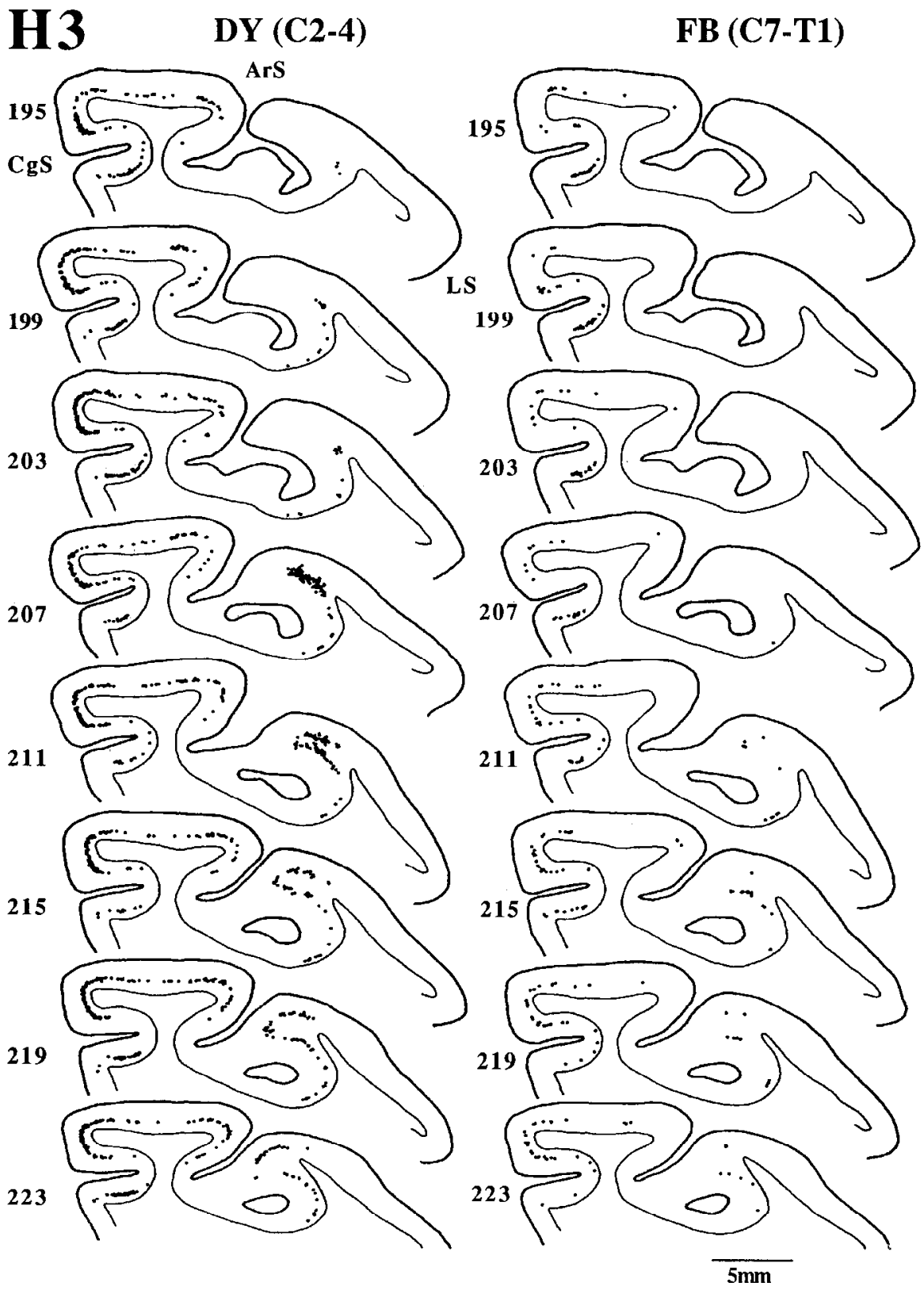

amounts of the primary motor cortex were allotted to dense projections to upper and lower cervical segments (Table 4). On the other hand, the PMd and the "lateral" cervical region in the primary motor cortex (see Table 5) were quite similar in the ratio of the amount of cortex allotted to dense projections to upper and lower cervical segments.

The caudomedial region of the PMd that projects most densely to lower cervical segments corresponds closely to the region of area 6 where recording studies have found neurons related to the preparation and execution of hand movements (e.g., see Fig. 6 of Kurata, 1989; see also Kurata et al., 1985). Likewise, the rostrolateral region of the PMd that projects most densely to upper cervical segments corresponds closely to the region of area 6 where neurons were related to the preparation and execution of more proximal forelimb movements (e.g., Weinrich and Wisc, 1982; Weinrich et al., 1984; Kurata and Wise 1988a,b; Hocherman and Wise, 1991). Thus, the topographic organiza- tion of corticospinal projections we have observed in the PMd may reflect an underlying somatotopic organization in this cortical area.

\section{Discussion}

There are three major observations of the present study. First, we found two separate regions within area 4 that send corticospinal projections primarily to the lower cervical segments (Fig. 14). We will argue that this result is evidence for two spatially separate distal representations in the "arm" area of the primary motor cortex (see summary diagram, Fig. 18). Second, we found that corticospinal projections to cervical and lumbar segments of the spinal cord originate from topographically separate regions of not only the primary motor cortex, but also the PMd (Fig. 5). This result implies that, like the primary motor cortex, the PMd has a distinct representation of the arm and leg (see summary diagram, Fig. 17). We have also found ana- 
tomical evidence for a limited topography within the PMv (Figs. $8,10,14$; see also summary diagram, Fig. 17). Third, we found that the densest corticospinal projections to upper cervical and lower cervical segments originate from largely separate regions of the PMd (Fig. 14). We will argue that this result indicates that the "arm" area of the PMd contains the representation of both distal and proximal body parts (see summary diagram, Fig. 18).

Before considering these findings further, it is important to examine a methodological concern associated with our study. We have exploited the segmental organization of the spinal cord to reveal features of cortical topography and, in particular, the issue of somatotopic organization in the premotor arcas and the primary motor cortex. The only significant limitation of this approach is that the segmental organization of the spinal cord is not equivalent to a precise somatotopic organization.

It is clear that tracer injections into lower cervical (C7-T1) segments involve regions of the spinal cord that are primarily concerned with the control of the arm (Kuypers, 1981). Similarly, tracer injections into lower lumbosacral segments (L6-S1) involve regions of the spinal cord that are primarily concerned with the control of the leg (Kuypers, 1981). As a consequence, it is reasonable to conclude that the topographic patterns of labeling observed in experiments with tracer injections at these segmental levels reflect the location of arm and leg representation in each cortical area.

The situation is not as clear for comparisons between tracer injections into upper cervical (C2-C4) and lower cervical segments (C7-T1). Upper cervical segments are primarily concerned with the control of proximal and axial musculature including the shoulder and neck (Kendall et al., 1971; Rapoport, 1978; Richmond et al., 1978; Karim and Nah, 1981; Augustine and White, 1986; Jenny et al., 1988; Ueyama et al., 1990). In addition, in the cat there is evidence for a set of interneurons in upper cervical segments (from caudal $\mathrm{C} 2$ to rostral $\mathrm{C} 5$ ) that are involved in the control of "targeted reaching movements" of the forelimb (Alstermark et al., 1981; Alstermark and Kummel, 1990a,b; Alstermark et al., 1990). These interneurons project monosynaptically to forelimb motoneurons via short propriospinal connections and receive convergent inputs from cortico-, rubro-, tecto-, and reticulospinal fibers (Illert et al., $1976,1977,1978)$. There is physiological evidence that these propriospinal neurons make monosynaptic connections with motoneurons that innervate distal as well proximal musculature (Alstermark and Sasaki, 1985, 1986; Alstermark et al., 1991). A tracer injection into upper cervical segments would involve not only the neck and shoulder motoneurons in these segments, but also interneurons, some of that may influence motoneurons in lower cervical segments that innervate more distal musculature.

Analogous problems are encountered with tracer injections into lower cervical segments. The motoneurons that innervate hand muscles are exclusively located in these segments (Kuypers, 1981; Jenny and Inukai, 1983). However, lower cervical segments also contain some motoneurons that innervate more proximal muscles like triceps and pectoralis (Jenny and Inukai, 1983). Furthermore, the medial cell column of motoneurons that innervates axial muscles extends throughout the cervical enlargement (Sherrington, 1898; Reed, 1940; Sprague, 1948; Kuypers, 1981). A tracer injection into lower cervical segments would involve not only motoncurons innervating distal forelimb muscles, but also some motoneurons innervating more proximal and axial muscles. In addition, such tracer injections involve the complex set of interneurons that are located in these segments (e.g., Alstermark and Kummel, 1990a,b).

In the discussion that follows, we have based our interpretations about cortical somatotopy on the relative amount of proximal and distal representation at each cervical level. Clearly, the interneurons and motoneurons that influence the control of distal muscles are most heavily represented in lower cervical segments, whereas those interneurons and motoneurons that influence the control of more proximal muscles are most heavily represented in upper cervical segments. Based on this arrangement, it is likely that the peak density of labeled neurons created by tracer injections into lower cervical segments will, in most instances, reflect the location of corticospinal neurons concerned with the control of distal forelimb movements. Similarly, the peaks created by injections into upper cervical segments will largely reflect the location of corticospinal neurons concerned with the control of more proximal forelimb movements. However, given the lack of a precise somatotopic organization within the cervical segments, our conclusions regarding the maps of arm representation in different cortical areas should be tested with alternative methods such as mapping motor responses with intracortical stimulation.

\section{Topographic organization of the corticospinal system}

Primary motor cortex. In general, the present and prior studies on the topographic origin of corticospinal projections from the primary motor cortex (e.g., Liu and Chambers, 1964; Kuypers and Brinkman, 1970; Biber ct al., 1978; Murray and Coulter, 1981) have found a close correspondence between the location of the "arm" and "leg" representations defined anatomically and their location defined using surface or intracortical stimulation (Woolsey et al., 1952; Kwan et al., 1978; Wise and Tanji, 1981; Sessle and Wiesendanger, 1982; Kurata, 1989; Sato and Tanji, 1989). The use of multiple tracers in single animals allowed us to demonstrate directly that projections from the primary motor cortex to fore- and hindlimb regions of the spinal cord originate from spatially separate populations of corticospinal neurons. In fact, we found that very few neurons were double labeled following tracer injections into lower cervical and lower lumbosacral segments $(0.2 \%)$ and that there was little intermingling of neurons that were labeled from the different injection sites.

Corticospinal projections to upper and lower cervical segments also originate from largely scparatc populations of neurons. We found that $4 \%$ of the corticospinal neurons in the primary motor cortex were double labeled after tracer injections into upper and lower cervical segments. Similarly, in a physiological study on the primary motor cortex of the cebus monkey, Shinoda et al. (1979) found that only 4 of 101 neurons that projected to lower cervical segments $(\mathrm{C} 7, \mathrm{C} 8$, and $\mathrm{T} 1)$ also sent a branch to $\mathrm{C} 5$. Thus, although the axons of corticospinal neurons may arborize extensively in the spinal cord, there appear to be some limits to their segmental spread.

On the other hand, we found extensive intermingling of corticospinal neurons that project to upper cervical segments with those that project to lower cervical segments. There are several possible interpretations of this result. As noted above, there is only a loose correspondence between the segmental organization of the cervical spinal cord and a somatotopic map of the upper limb. It is possible that the intermingling of different populations of corticospinal neurons simply reflects the mixing of different 
motoneuron and interneuron pools within the cervical cord. It is also possible that the intermingling actually reflects an interleaving at the cortical level of neurons that influence different forelimb muscles. If true, this intermingling may have some functional significance (e.g., Evarts, 1967, 1981; Jankowska et al., 1975). For example, overlap in the representation of different muscles within the cortex has been suggested as an atomical substrate for coordinating the activity of muscles that act about a single joint or across two adjacent joints (e.g., Kwan et al., 1978; Humphrey and Reed, 1983; Humphrey, 1986; Humphrey and Tanji, 1991). Unfortunately, the proccdures we have used to define the origin of different populations of corticospinal neurons do not allow us to determine which of these or other potential interpretations of the intermingling we observed is correct.

Perhaps of more importance than the intermingling of different populations of corticospinal neurons is our observation that the regions of area 4 that project most densely to upper cervical segments are surprisingly separate from those that project most densely to lower cervical segments. Furthermore, we found that there are multiple peaks in the density of corticospinal neurons that project to a particular cervical level. The most dramatic example of this is the separate medial and lateral peaks in the density of area 4 neurons that project to lower cervical segments (i.e., the medial and lateral LC peaks). Comparable variations in the density of corticospinal neurons within area 4 have not been described previously.

There are at least two interpretations of the functional significance of the medial and lateral LC peaks. As noted above, lower cervical segments contain motoneurons and interneurons that influence the control of hand muscles. However, they also contain some motoneurons and interneurons that influence the control of proximal and axial musculature. It is possible that one peak reflects the location of a hand representation and the other reflects the location of a representation for a more proximal and axial part of the body. Some support for this interpretation comes from the results of Kuypers and Brinkman (1970) on the pattern of termination within the spinal cord of efferents from different regions of area 4 . They found that efferents from a caudolateral region of area 4 (comparable in location to the lateral LC peak) terminate most heavily in dorsolateral parts of the spinal cord intermediate zone and in adjaccnt parts of the ventral horn. In contrast, efferents from a more medial portion of area 4 (comparable in location to the medial LC peak) terminate most heavily in ventromedial parts of the spinal cord intermediate zone. They argued that the efferents terminating in dorsolateral parts of the intermediate zone would primarily influence muscles intrinsic to the limbs, and that efferents terminating more ventromedially would primarily innervate girdle and body muscles (for review and references, see Kuypers, 1981). Based on their data, the lateral LC peak would influence the control of distal limb musculature and the medial LC peak would influence the control of more proximal and axial musculature.

An argument against this view is the complete absence of any overlap of the medial LC peak with regions of cortex that project densely to upper cervical segments (i.e., the medial UC peak) where the control of proximal/axial musculature is most densely represented. Furthermore, the notion that the medial LC peak reflects the location of a proximal/axial representation is not consistent with our observation that this peak is only slightly smaller and has the same number and density of corticospinal neurons as the lateral LC peak. Given that lower cervical segments contain a large representation of distal muscles and a much less substantial representation of proximal muscles, it seems reasonable to expect that the pattern of corticospinal projections to this segmental level would reflect this disparity. Thus, if the medial LC peak reflects the location of a proximal/ axial representation, then it is surprising that it is not much less substantial than the lateral LC peak.

Another interpretation, which we favor, is that our findings provide anatomical evidence for separate medial and lateral hand representations in area 4 . Therc is strong physiological support for a hand representation (fingers and wrist) at the site in area 4 where the lateral LC peak is located (e.g., Woolsey et al., 1952; Kwan et al., 1978; Sessle and Wiesendanger, 1982; Humphrey and Reed, 1983; Humphrey, 1986; Sato and Tanji, 1989). Unfortunately, the region of area 4 where the medial LC peak is located has not been mapped extensively. As a consequence, only scant information is available about the body parts represented at this site. According to the classical map generated by electrical stimulation of the cortical surface, the medial LC peak is located in a region of area 4 that is at the border between the fore- and hindlimb representations (see Woolsey et al., 1952, their summary diagram, Fig. 131). However, in one of the individual experiments that was illustrated (Woolsey et al., 1952, their Fig. 125, experiment 9), wrist movements (along with movements of the hindlimb) were evoked from several sites that were betwecn the represcntations of the shoulder and leg. In addition, the composite figurine chart that summarized the results of several experiments (Woolsey et al., 1952, their Fig. $132 a$ ) indicates that wrist movements were evoked from two sites just caudal to the $\mathrm{SPCS}$ and medial to the representation of the elbow and shoulder. These sites are at approximately the same location as our medial LC peak.

Some additional support for a hand representation at the site of the medial LC peak comes from two recent studies that used intracortical stimulation to map the primary motor cortex (Waters et al., 1990; Huntley and Jones, 1991). In two out of four baboons examined, a second small representation of the digits was found in a region of the primary motor cortex that was 5 $\mathrm{mm}$ medial to the main representation of the hand (see Waters et al., 1990, their Fig. 5). Likewise, in one of the macaques examined by Huntley and Jones (1991; see their Fig. 10), there was suggestive evidence for a second small hand representation located $3 \mathrm{~mm}$ medial to the main representation of the hand in the primary motor cortex.

There is also some evidence that our medial and lateral LC peaks are specifically interconnected. A small injection of a retrograde tracer placed into the "lateral portion of the forelimb representation" (comparable to our lateral LC peak) labeled large numbers of neurons $2-3 \mathrm{~mm}$ medial to the injection site (comparable to our medial LC peak; Ghosh et al., 1987, their Fig. 4, animal M1). The cortical region lying between these labeled neurons and the injection site contained few labeled neurons. Thus, the available evidence, albeit limited, supports our interpretation that a hand representation is located at the site of the medial LC peak. Clearly, the pattern of body representation in the region of area 4 that lies at the border of the arm and leg representations needs to be more thoroughly explored. If our interpretation of the medial peak is correct, then this region of area 4 should contain a representation of the fingers and wrist that is in some respects comparable to the classical hand representation located at the site of the lateral LC peak. 


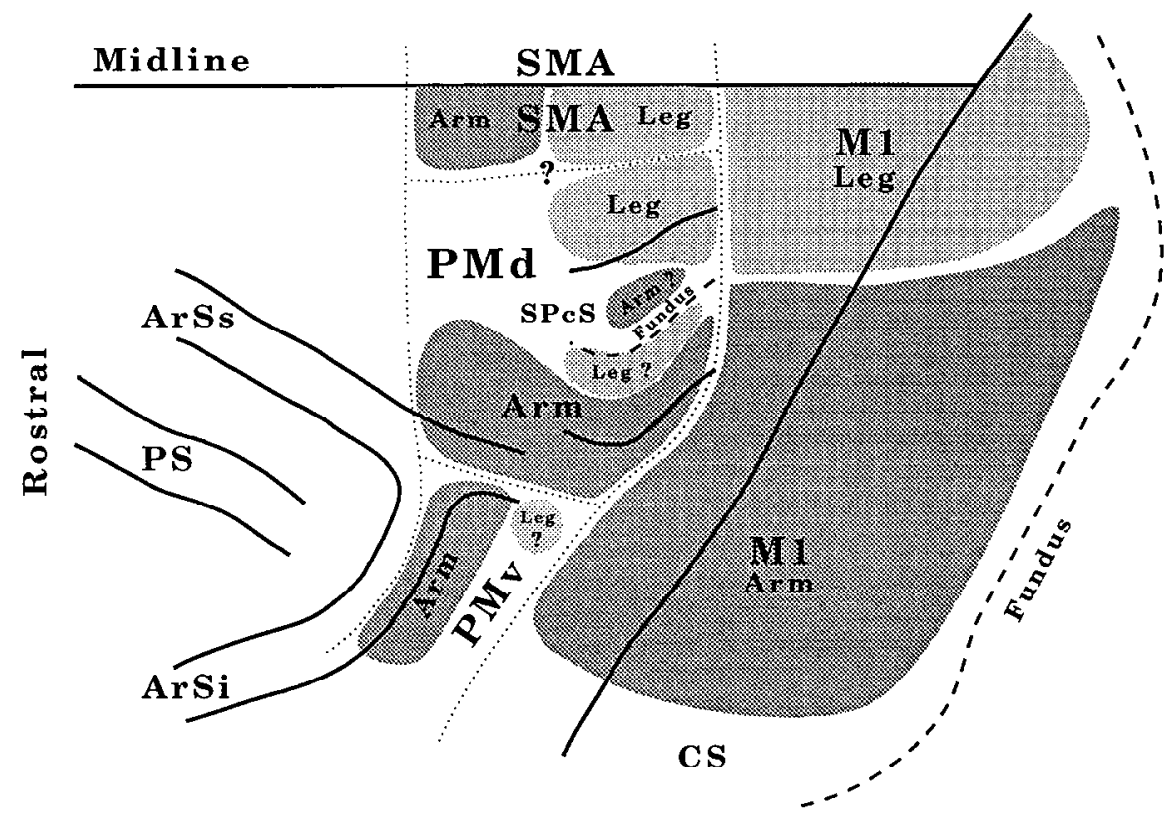

Figure 17. Arm and leg representations in the primary motor cortex and the premotor areas on the lateral surface of the hemisphere. The patterns of arm and leg representation found in each motor area are summarized in this diagram. This map is based primarily on the topographic distribution of corticospinal neurons labeled following tracer injections into lower cervical and lower lumbosacral segments of spinal cord (e.g., H1, Fig. 5A; see also H2, Fig. $5 B$, and $\mathrm{K} 3$, Fig. $8 B$ ). Note that this map differs from the classical map shown in Figure 4 (top). $L / T$, leg and or lower trunk. See Discussion for further description and discussion. See Figure 4 for abbreviations.

The presence of a separate hand representation at each LC peak would be a significant departure from the classical picture of forelimb representation depicted by Woolsey et al. (1952).

$P M d$. Our studies indicate that there is a distinct topographic organization of corticospinal efferents within the PMd. Before discussing this result, it is important to point out that there has been a long-standing controversy about the existence of a premotor area in this region of cortex. The PMd is located within the region Woolsey et al. (1952) considered the rostral part of their "precentral motor area." Indeed, they placed the representation of axial musculature within this region of cortex (see Fig. 4, top) and viewed this part of the body map as "the cement that binds the pattern [of total body representation] together" (p 257). Furthermore, Woolsey et al. (1952) used the presence of an axial representation at this cortical site as one of their principal arguments against the concept of a premotor area.

In contrast, contemporary studies have demonstrated a number of important anatomical and physiological differences between the PMd and the primary motor cortex (for a more detailed discussion, see Dum and Strick, 1991b). Three differences are particularly notable. First, the threshold current required to evoke movements with microstimulation is generally higher in the PMd than in the primary motor cortex (Sessle and Wiesendanger, 1982; Weinrich and Wise, 1982; Kurata and Tanji, 1986; Kurata, 1989). Second, compared to the primary motor cortex, there are fewer large neurons in layer V of the PMd (Weinrich and Wise, 1982; Kurata and Tanji, 1986; Riehle and Requin, 1989; Caminiti et al., 1991; Dum and Strick, 1991b; Hocherman and Wise, 1991). Third, a larger percentage of "set-related" neurons are found in the PMd than in the primary motor cortex (Godschalk et al., 1981; Weinrich and Wise, 1982; Weinrich et al., 1984; Kurata et al., 1985; Kurata and Wise, 1988a,b; Kurata, 1989). The full extent of the PMd has not been precisely defined. However, its rostral border with more anterior portions of area 6 (e.g., area $6 \mathrm{a} \beta$ ) is clearly marked by the virtual disappearance of corticospinal neurons (see also Dum and Strick, 1991b). This border is located at approximately the level of the genu of the ArS. The lateral border of the PMd with the PMv is thought to be marked by the spur of the ArS (Matelli et al., 1985; Barbas and Pandya, 1987; Hocherman and Wise, 1991), although the location of this landmark can vary considcrably in different macaques. Despite the uncertainty about its exact borders, there is now general agreement that the PMd represents a premotor area that has anatomical and physiological features that are quite distinct from the primary motor cortex.

Although important differences exist, the present study indicates that the PMd is similar to the primary motor cortex in three noteworthy respects. First, the PMd has substantial projections to the spinal cord. Previously, it had been suggested that an important difference between the PMd and the primary motor cortex was that corticospinal neurons were largely absent from the PMd (e.g., Sessle and Wiesendanger, 1982). Our results do not support this suggestion, and instead confirm our prior observation that the density of corticospinal neurons in the PMd is comparable to that in the primary motor cortex (see also Dum and Strick, 1991b). This result has led us to view the PMd as one of a set of cortical areas that, like the primary motor cortex, has the potential to influence directly the generation and control of movement at the level of the spinal cord (Dum and Strick, 1991a,b).

Second, the PMd, like the primary motor cortex, contains separate representations of the arm and leg (Fig. 17). In general, we found that neurons in the PMd that project to lower cervical segments are separate from and located largely lateral to those that project to lower lumbosacral segments. These findings support our previous suggestions that the PMd is somatotopically organized (Muakkassa and Strick, 1979; Strick, 1985; see also Godschalk et al., 1984). However, a precise somatotopic organization, with a leg representation located entirely medial to an arm representation, does not characterize all of this premotor area. At the interface between the arm and leg representations (i.e., in regions of the PMd that are buried within the SPcS), a small "island" of corticospinal neurons that innervates lower cervical segments is embedded within the lateral part of the PMd leg representation (Fig. 17). A similar small "island" of corticospinal neurons that innervates lower lumbosacral segments is found within the medial part of the PMd arm representation (Fig. 17). In physiological studies, Kurata (1989) also 
Figure 18. Proximal and distal representation in the arm areas of the primary motor cortex and the premotor areas on the lateral surface of the hemisphere. This map is based on the peaks in the distribution of corticospinal neurons labeled following tracer injections into lower cervical and upper cervical segments (e.g., H3, Figs. 12, 14A; see also $\mathrm{H} 2$, Fig. $7 B$, and $\mathrm{H} 7$, Figs. $13,14 B$ ). Note that the map shows (1) distinct proximal and distal representations in the primary motor cortex and the PMd, and (2) two distal representations in the primary motor cortex. $D$, distal; $P$, proximal. See Discussion for further description and discussion. See Figure 4 for abbreviations.

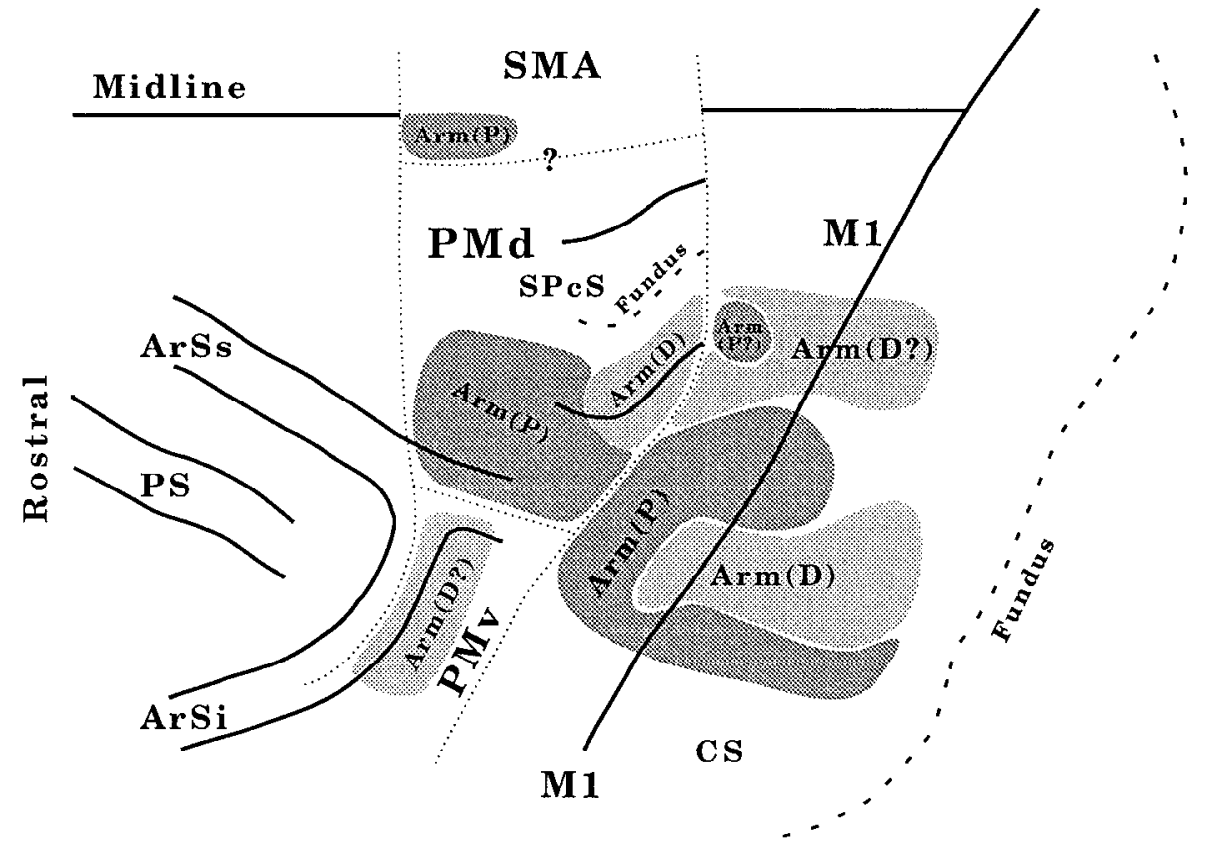

failed to observe a "rigid boundary" between the forelimb and hindlimb representations in the PMd. The significance of the two "islands" of corticospinal neurons and the disruptions in somatotopic organization they cause is unclear, but they may reflect some unique function for regions of the PMd that are near the SPcS.

The third important respect in that the PMd is similar to the primary motor cortex is that the distal as well as the proximal forelimb are represented in the "arm" areas of both cortical regions (Fig. 18). We found that the regions of the PMd that project most densely to lower cervical segments are located caudal and medial to the regions of the PMd that project most densely to upper cervical segments. Furthermore, there is very limited overlap in the origin of dense projections from the PMd to these different cervical levels. Based on the pattern of body representation in the cervical segments (see discussion above), these results imply that the "arm" area in the PMd, like that in the primary motor cortex, contains separate distal and proximal representations.

The conclusion that the "arm" area of the PMd includes some distal representation clearly contrasts with the classical map that placed the representation of axial and proximal musculature in this region of cortex (see discussion above; see also Woolsey et al., 1952). The existence of distal representation in regions of the PMd that are in and just lateral to the SPcS is supported by anatomical findings that this region of cortex is interconnected with the hand representation of the primary motor cortex (e.g., Muakkassa and Strick, 1979; Godschalk et al., 1984; Strick, 1985). Because the PMd is "less excitable" than the primary motor cortex, there is no detailed motor map of the PMd. Nevertheless, there is limited physiological support for our conclusion that the "arm" area of the PMd contains some distal representation. A close inspection of the data from Woolsey's study shows that wrist and forearm movements were evoked from several sites that were lateral to the $\mathrm{SPcS}$, a region that would now be considered as part of the PMd (Woolsey et al., 1952, their Fig. 125, experiment 9; Fig. 126, experiment 19; and Fig. $132 a$, composite figurine chart). In addition, Huntley and Jones (1991) observed that, in two macaques, intracortical stimulation at multiple sites that were rostral and medial to the classical hand representation in area 4 evoked digit or wrist movements (see their Figs. 1 $B, 10 A$ ). Gould et al. (1986) mapped the motor cortex of owl monkeys with intracortical stimulation and found that wrist movements could be evoked from a cortical region that appears to be comparable to the PMd in macaques (see their Fig. 5, experiment 83-15, and Fig. 11, experiment 83-50). Unfortunately, neither Huntley and Jones (1991) nor Gould et al. (1986) defined the area $4 / 6$ border. As a consequence, the precise location of their stimulation sites relative to the PMd is uncertain. In preliminary studies, we have been able to evoke digit and wrist movements with intracortical stimulation in the lateral bank of the SPcS, a cortical region clearly within the PMd (R. P. Dum and P. L. Strick, unpublished observations). Thus, although a more detailed motor map of the body remains to be determined for the PMd, the available physiological evidence supports the existence of some distal representation in this premotor area.

Our measurements suggest that, within the "arm" area of the PMd, proximal representation occupies a somewhat larger area of cortex than distal. In contrast, in the "arm" area of the primary motor cortex (i.e., the lateral UC and LC peaks together with the medial UC and LC peaks), proximal and distal representations occupy about the same amount of cortex (Table 4 , compare the area of UC peaks with the area of LC peaks in M1). As noted above, the classical "arm" area of the primary motor cortex includes only the cortex containing the lateral UC and $I C$. peaks. If just this region of area 4 is considered, proximal representation occupies a larger amount of cortex than distal (compare the area of lateral UC peaks with the area of lateral LC peaks in Table 5). In fact, the ratio of proximal to distal representation in this portion of area 4 is approximately the same as that in the PMd (1.6:1). Thus, there does not appear to be any greater emphasis on the representation of proximal musculature in the PMd than there is in the classical "arm" area of the primary motor cortex. This result has some relevance for proposals about the function of the PMd. One common notion about the function of premotor cortex is that it contributes to stabilizing the limb primarily or exclusively through the 
control of proximal and axial musculature (for discussion, see Humphrey, 1979; Wiesendanger, 1981; Wise, 1985). Our observations suggest that it is unlikely that this proposal reflects the function of the PMd. Rather, our findings emphasize that any concept about the function of this premotor area should include its involvement in the control of distal musculature.

$P M v$. The results of the present study confirm our previous reports that the PMv has a corticospinal projection that is focused on upper cervical segments (Martino and Strick, 1987; Dum and Strick, 1989, 1991b). In addition, we found a small number of neurons in the PMv that project to spinal segments below T7. However, the axons of these neurons do not extend as far as the lower lumbosacral segments since no labeled neurons were found in the PMv after tracer injections into this level of the spinal cord. Thus, the PMv is unique among the premotor areas in having corticospinal projections that target specific spinal segments. All of the other premotor areas, including those on the medial wall of the hemisphere, have neurons that project throughout the cervical and lumbosacral spinal cord.

The neurons in the PMv that project to segments below T7 are located just caudal and lateral to the spur of the ArS. This is the same region where recording studies in awake monkeys found neurons that showed changes in activity specifically related to foot and not hand movements (Kurata et al., 1985; Kurata, 1989). Although our data on PMv projections to spinal segments between $\mathrm{T} 7$ and the lower lumbosacral cord are admittedly limited, this correspondence suggests that the PMv may have a small representation of the leg and/or lower trunk (Fig. 17). Since the region of the PMv that projects to upper cervical segments is located rostral and lateral to the region that projects to segments below $\mathrm{T} 7$, there appears to be a semblance of a body map in the PMv (Fig. 17). However, the present results do not support our earlier proposal that the "leg" area of the PMv was located near the superior limb of the ArS (Muakkassa and Strick, 1979). This proposal was probably due to a misinterpretation of the cortical areas involved in the large injection sites that were used in the earlier study.

The PMv also is unique among the premotor areas in that corticospinal projections originate only from specific regions within the PMv and not from all parts of this premotor area. The corticospinal projection to cervical segments originates from the rostral part of the PMv that is largely buried in the caudal bank of the ArS. This appears to be the same region of the PMv that projects to the "hand" area of the primary motor cortex (Muakkassa and Strick, 1979; Strick, 1985; see also Matsumura and Kubota, 1979; Godschalk et al., 1984). Intracortical stimulation in rostral PMv evokes movements of the fingers and wrist (Gentilucci et al., 1988, 1989). Neurons in rostral PMv show changes in activity related to active movements of the hand, and some neurons are activated by tactile stimulation of the hand (Rizzolatti et al., 1981a; Gentilucci et al., 1988). The rostral PMv receives its most substantial thalamic input from area X, a major target of cerebellar efferents (Schell and Strick, 1984; Matelli et al., 1989). In contrast, the more caudal part of the PMv does not project to the spinal cord and receives substantial thalamic input both from the nucleus ventralis lateralis pars oralis (VLo), a major target of pallidal efferents, and from area X (Matelli et al., 1989, their Fig. 15, animal IT4-7, right). Intracortical stimulation in caudal PMv evokes movements at more proximal joints (Gentilucci et al., 1988, 1989). Neurons in caudal PMv show changes in activity related to movements of the whole arm and mouth, and some neurons are activated by tactile stimulation of the shoulder, chest, and face (Rizzolatti et al., 1981a; Gentilucci et al., 1988). Thus, corticospinal projections to the cervical cord originate only from the rostral portion of the PMv where the hand is represented and not from the caudal portion where more proximal body parts are represented. The functional significance of this arrangement is not fully apparent. However, it certainly implies that the rostral portion of the PMv that controls hand movement has a more direct access to motor output at the spinal level than other regions of the PMv.

There is an obvious disparity between the cervical level of termination of corticospinal efferents from the PMv and the body part represented at the origin of this projection. As indicated above, corticospinal efferents originate largely from the rostral part of the PMv that is the site of a potential "hand" area. Yet, this portion of the PMv projects specifically upon upper cervical segments. Previously, we suggested that this disparity could reflect a projection of corticospinal efferents from the $\mathrm{PMv}$ to propriospinal neurons in $\mathrm{C} 2-\mathrm{C} 4$ that in turn innervate the motoneurons in lower cervical segments that control hand muscles (Martino and Strick, 1987; Dum and Strick, 1989; see also Gentilucci et al., 1988). There is evidence for such propriospinal neurons at $\mathrm{C} 2-\mathrm{C} 4$ in the cat (Illert et al., 1976, 1977, 1978; Alstermark and Sasaki, 1985, 1986; Alstermark and Kummel, 1990a,b; Alstermark et al., 1990); however, they remain to be demonstrated in primates. At this point, almost nothing is known about the spinal neurons that receive input from the PMv or, for that matter, any other premotor area, and much more information should be gathered on this issue. Nevertheless, if our speculation about the spinal connections of the PMv is correct, it suggests that a portion of the corticospinal system can target a restricted set of the spinal interneurons that control hand motoneurons. This raises the possibility that individual premotor areas might target unique sets of spinal circuits. As a first step in exploring this possibility, we have begun to examine the patterns of termination within the spinal cord of efferents from the premotor areas.

Finally, the observations of the present study support our initial suggestion that the PMv and PMd are distinct premotor areas (Muakkassa and Strick, 1979). There are obvious differences in the organization of corticospinal projections from the two regions. For example, substantially more corticospinal neurons are found in the PMd than in the PMv (Table 6). Also, corticospinal efferents originate from all parts of the PMd and project to all cervical and lumbosacral levels (Table 6). In contrast, corticospinal efferents originate from a restricted part of the PMv and are focused on specific spinal segments. In Table 6 , we have summarized some of the other striking anatomical and physiological differences between the PMv and PMd. These two premotor areas clearly receive different patterns of input from regions of parietal and prefrontal cortex (Chavis and Pandya, 1976; Godschalk et al., 1984; Petrides and Pandya, 1984; Matelli et al., 1986; Ghosh et al., 1987; Cavada and GoldmanRakic, 1989; Preuss and Goldman-Rakic, 1989; Lu and Strick, 1990; Dum and Strick, 1991a; Kurata, 1991). Quantitative and potentially qualitative differences appear to exist for neuron activity in the PMd and PMv related to the preparation, triggering, and execution of trained limb movements (Kubota and Hamada, 1978; Rizzolatti et al., 1981a,b, 1988; Weinrich and Wise, 1982; Weinrich et al., 1984; Godschalk et al., 1985; Kurata et al., 1985; Kurata and Wise, 1988a,b; Kurata, 1989; Mushiake et al., 1991). Furthermore, the PMd and PMv may receive different patterns of thalamic input. Although the origin of thalamic inputs to the PMd has not been specifically exam- 
Table 6. Contrasting features of the PMd and PMv

\begin{tabular}{|c|c|c|c|}
\hline & PMd & PMv & References \\
\hline \multicolumn{4}{|l|}{ Neurophysiological properties } \\
\hline $\begin{array}{l}\text { Signal-related activity } \\
\text { Set-related activity }^{b} \\
\text { Movement-related activity }\end{array}$ & $\begin{array}{l}+ \\
++++ \\
+++\end{array}$ & $\begin{array}{l}+++ \\
++ \\
+++\end{array}$ & $\begin{array}{l}\text { Kubota and Hamada, 1978; Rizzolatti et al., 1981a,b, 1988; } \\
\text { Weinrich and Wise, 1982; Weinrich et al., 1984; Godschalk et } \\
\text { al., 1985; Kurata et al. 1985; Gentilucci et al., 1988; Kurata } \\
\text { and Wise, 1988a,b; Kurata, } 1989\end{array}$ \\
\hline $\begin{array}{l}\text { "Sequence-specific" activityd } \\
\text { "Transition-specific" activitye }\end{array}$ & $\begin{array}{l}++ \\
+\end{array}$ & $\begin{array}{l}- \\
++\end{array}$ & Mushiake et al., 1991 \\
\hline \multicolumn{4}{|l|}{ Cortical connections } \\
\hline $\begin{array}{l}\text { Rostral M1 } \\
\text { Caudal M1 } \\
\text { SMA } \\
\text { Subfields of Area } 5 \\
\text { Subfields of Area } 7 \\
\text { SII and areas in the lateral sulcus }\end{array}$ & $\begin{array}{l}++++ \\
- \\
+++ \\
++++ \\
+ \\
+\end{array}$ & $\begin{array}{l}+++ \\
++ \\
++ \\
+ \\
++++ \\
+++\end{array}$ & $\begin{array}{l}\text { Chavis and Pandya, 1976; Muakkassa and Strick, 1979; } \\
\text { Godschalk et al., 1984; Petrides and Pandya, 1984; } \\
\text { Wiesendanger and Wiesendanger, 1984; Matelli et al., 1986; } \\
\text { Ghosh et al., 1987; Cavada and Goldman-Rakic, 1989; Dum } \\
\text { and Strick, 1991a; Kurata, } 1991\end{array}$ \\
\hline Prefrontal cortex & $-1+$ & +++ & Preuss and Goldman-Rakic, 1989; Lu and Strick, 1990 \\
\hline \multicolumn{4}{|l|}{ Corticospinal projections } \\
\hline $\begin{array}{l}\text { Upper cervical } \\
\text { Lower cervical } \\
\text { Thoracic } \\
\text { Lower lumbosacral }\end{array}$ & $\begin{array}{l}++++ \\
++++ \\
++++ \\
++++\end{array}$ & $\begin{array}{l}+++ \\
+ \\
+ \\
-\end{array}$ & $\begin{array}{l}\text { Martino and Strick, 1987; Dum and Strick, 1989, 1991b; } \\
\text { present study }\end{array}$ \\
\hline
\end{tabular}

a A change in activity when the external cue is presented.

"A change in activity during the period when the animal is preparing to make a movement.

'A change in activity just before and/or during the movement.

${ }^{a} \mathrm{~A}$ change in activity when a particular sequence of the key presses is performed.

"A change in activity during the "transitional phase" of switching from one motor task to another.

ined, the results of Kievit and Kuypers (1977) could be interpreted to suggest that PMd receives its most substantial input from a distinct subdivision of the ventrolateral thalamus, ventralis lateralis pars caudalis. In contrast, as noted above, the PMv receives its most substantial input from parts of area $X$ and VLo. If future anatomical, physiological, and behavioral studies are careful to distinguish between the PMd and PMv, it is likely that additional, perhaps more striking differences between the two premotor areas will emerge. However, based on the data presently available, we believe that there is no longer any justification for viewing the PMd and PMv as parts of a single undifferentiated field termed premotor cortex.

\section{References}

Alstermark B, Kummel H (1990a) Transneuronal transport of wheat germ agglutinin conjugated horseradish peroxidase into last order spinal interneurones projecting to acromio- and spinodeltoideus motoneurones in the cat. 1. Location of labelled interneurones and influence of synaptic activity on the transneuronal transport. Exp Brain Res 80:83-95.

Alstermark B, Kummel H (1990b) Transneuronal transport of wheat germ agglutinin conjugated horseradish peroxidase into last order spinal interneurones projecting to acromio- and spinodeltoideus motoneurones in the cat. 2. Differential labelling of interneurones depending on movement type. Exp Brain Res 80:96-103.

Alstermark B, Sasaki S (1985) Integraticn in descending motor pathways controlling the forelimb in the cat. 13. Corticospinal effects in shoulder, elbow, wrist, and digit motor-neurons. Exp Brain Res 59: 353-364.

Alstermark B, Sasaki S (1986) Integration in descending motor pathways controlling the forelimb in the cat. 15 . Comparison of the projection from excitatory $\mathrm{C} 3-\mathrm{C} 4$ propriospinal neurones to different species of forelimb motoneurones. Exp Brain Res 63:543-556.

Alstermark B, Lundberg A, Norrsell U, Sybirska E (1981) Integration in descending motor pathways controlling the forelimb in the cat. Exp Brain Res 42:299-318.

Alstermark B, Kummel H, Pinter MJ, Tantisira B (1990) Integration in descending motor pathways controlling the forelimb in the cat. 17 . Axonal projection and termination of $\mathrm{C} 3-\mathrm{C} 4$ propriospinal neurones in the C6-Thl segments. Exp Brain Res 81:447-461.

Alstermark B, Isa T, Tantisira B (1991) Integration in descending motor pathways controlling the forelimb in the cat. 18. Morphology, axonal projection and termination of collaterals from $\mathrm{C} 3-\mathrm{C} 4$ propriospinal neurones in the segment of origin. Exp Brain Res 84:561568.

Augustine JR, White JF (1986) The accessory nerve nucleus in the baboon. Anat Rec 214:312-320.

Barbas H, Pandya DN (1987) Architecture and frontal cortical connections of the premotor cortex (area 6 ) in the rhesus monkey. J Comp Neurol 256:211-228.

Bentivoglio M, Kuypers HGJM, Catsman-Berrevoets CE, Loewe H, Dann O (1980) Two new fluorescent retrograde neuronal tracers, which are transported over long distance. Neurosci Lett 80:25-30.

Biber MP, Kneisley LW, LaVail JH (1978) Cortical neurons projecting to the cervical and lumbar enlargements of the spinal cord in young and adult rhesus monkeys. Exp Neurol 59:492-508.

Caminiti R, Johnson PB, Galli C, Ferraina S, Burnod Y (1991) Making arm movements within different parts of space: the premotor and motor cortical representation of a coordinate system for reaching to visual targets. J Neurosci 11:1182-1197.

Cavada C, Goldman-Rakic PS (1989) Posterior parietal cortex in rhesus monkey: II. Evidence for segregated corticocortical networks linking sensory and limbic areas with the frontal lobe. J Comp Neurol 287:422-445.

Chavis DA, Pandya DN (1976) Further observations on corticofrontal connections in the rhesus monkey. Brain Res 117:369-386.

Conde F (1987) Further studies on the use of the fluorescent tracers fast blue and diamidino yellow: effective uptake area and cellular storage sites. J Neurosci Methods 21:31-43.

Craig AD, Linington AJ, Kniffki KD (1989) Significant differences in the retrograde labeling of spinothalamic tract cells by horseradish 
peroxidase and the fluorescent tracers fast blue and diamidino yellow. Exp Brain Res 74:431-436.

Davidoff RA (1990) The pyramidal tract. Neurology 40:332-339.

Dum RP, Strick PL (1989) Corticospinal projections from the motor areas in the frontal lobe. In: Taniguichi symposia on brain sciences, No 12, Neural programming (M Ito, ed), pp 49-63. Tokyo: Japan Scientific Societies.

Dum RP, Strick PL (1991a) Premotor area: nodal points for parallel efferent systems involved in the central control of movement. In: Motor control: concepts and issues (Humphrey DR, Freund H-J, eds), pp 383-397. London: Wiley.

Dum RP, Strick PL (1991b) The origin of corticospinal projections from the premotor areas in the frontal lobe. J Neurosci 11:667-689.

Evarts EV (1967) Representation of movements and muscles by pyramidal tract neurons of the precentral motor cortex. In: Neurophysiological basis of normal and abnormal motor activities (Yahr MD, Purpura DP, eds), pp 215-253. Hewlett, NY: Raven.

Evarts EV (1981) Role of motor cortex in voluntary movements in primates. In: Handbook of physiology, $\mathrm{Sec} \mathrm{I}$, The nervous system, Vol II, Motor control, Pt I (Brooks VB, ed), pp 1083-1120. Bethesda, MD: American Physiological Society.

Freund HJ, Hummelsheim H (1985) Lesions of premotor cortex in man. Brain 108:697-733.

Gentilucci M, Fogassi L, Luppino G, Matelli M, Camarda R, Rizzolatti $G$ (1988) Functional organization of inferior area 6 in the macaque monkey. I. Somatotopy and the control of proximal movements. Exp Brain Res 71:475-490.

Gentilucci M, Fogassi L, Luppino G, Matelli M, Camarda R, Rizzolatti $G$ (1989) Somatotopic representation in inferior area 6 of the macaque monkey. Brain Behav Evol 33:118-121.

Ghosh S, Brinkman C, Porter R (1987) A quantitative study of the distribution of neurons projecting to the precentral motor cortex in the monkey (M. fascicularis). J Comp Neurol 259:424-444.

Godschalk M, Lemon RN, Nijs HGT, Kuypers HGJM (1981) Behavior of neurons in monkey peri-arcuate and precentral cortex before and during visually guided arm and hand movements. Exp Brain Res 44:113-136.

Godschalk M, Lemon RN, Kuypers HGJM, Ronday HK (1984) Cortical afferents and efferents of monkey postarcuate area: an anatomical and electrophysiological study. Exp Brain Res 56:410-424.

Godschalk M, Lemon RN, Kuypers HGJM, Van Der Steen J (1985) The involvement of monkey premotor cortex neurones in preparation of visually cued arm movements. Behav Brain Res 18:143-157.

Gould HJ, Cusick CG III, Pons TP, Kaas JH (1986) The relationship of corpus callosum connections to electrical stimulation maps of motor, supplementary motor, and the frontal eye fields in owl monkeys. J Comp Neurol 247:297-325.

He SQ, Dum RP, Strick PL (1989) Premotor areas on the medial wall of the hemisphere: corticospinal projections to cervical and lumbosacral cord. Soc Neurosci Abstr 15:282.

He SQ, Dum RP, Strick PL (1990) Premotor areas: corticospinal projections to upper and lower ecrvical cord. Soc Neurosci Abstr 16: 241 .

Hocherman S, Wise SP (1991) Effects of hand movement path on motor cortical activity in awake, behaving rhesus monkeys. Exp Brain Res 83:285-302.

Huisman AM, Kuypers HGJM, Conde F, Keizer K (1983) Collaterals of rubrospinal neurons to the cerebellum in rat. A retrograde fluorescent double labeling study. Brain Res 264:181-196.

Humphrey DR (1979) On the cortical control of visually directed reaching: contributions by nonprecentral motor area. In: Posture and movement (Talbott RE, Humphrey DR, eds), pp 51-112. New York: Raven.

Humphrey DR (1986) Representation of movements and muscles within the primate precentral motor cortex: historical and current perspectives. Fed Proc 45:2687-2699.

Humphrey DR, Reed DJ (1983) Separate cortical systems for the control of joint movement and joint stiffness: reciprocal activation and coactivation of antagonist muscles. Adv Neurol 39:347-372.

Humphrey DR, Tanji J (1991) What features of voluntary motor control are encoded in the neuronal discharge of different cortical motor areas? In: Motor control: concepts and issues (Humphrey DR, Freund H-J, eds), pp 413-443. London: Wiley.

Huntley GW, Jones EG (1991) Relationship of intrinsic connections to forelimb movement representation in monkey motor cortex: a correlative anatomic and physiological study. J Neurophysiol 66:390413.

Hutchins KD, Martino AM, Strick PL (1988) Corticospinal projections from the medial wall of the hemisphere. Exp Brain Res 71:667672.

Illert M, Lundberg A, Tanaka R (1976) Integration in descending motor pathways controlling the forelimb in the cat. 2 . Convergence on neurones mediating disynaptic cortico-motoneuronal excitation. Exp Brain Res 26:521-540.

Illert M, Lundberg A, Tanaka R (1977) Integration in descending motor pathways controlling the forelimb in the cat. 3 . Convergence on propriospinal neurons transmitting disynaptic excitation from the corticospinal tract and other descending tracts. Exp Brain Res 29: 323-346.

Illert M, Lundberg A, Padel Y, Tanaka R (1978) Integration in descending motor pathways controlling the forelimb in the cat. 5. Properties of and monosynaptic excitatory convergence on $\mathrm{C} 3-\mathrm{C} 4$ propriospinal neurons. Exp Brain Res 33:101-130.

Innocenti GM (1981) Growth and reshaping of axons in the establishment of visual callosal connections. Science 212:824-827.

Jankowska E, Padel Y, Tanaka R (1975) Projections of pyramidal tract cells to $\alpha$-motoneurones innervating hind-limb muscles in the monkey. J Physiol (Lond) 249:637-667.

Jenny A, Smith J, Decker J (1988) Motor organization of the spinal accessory nerve in the monkey. Brain Res 441:352-356.

Jenny AB, Inukai J (1983) Principles of motor organization of the monkey cervical spinal cord. J Neurosci 3:567-575.

Karim MA, Nah SH (1981) Localization of motoneurones innervating the sternocleidomastoid muscles in the monkey, rat and rabbit: a horseradish peroxidase study. Brain Res 206:145-148.

Keizer K, Kuypers HG (1989) Distribution of corticospinal neurons with collaterals to the lower brain stem reticular formation in monkey (Macaca fascicularis). Exp Brain Res 74:311-318.

Keizer K, Kuypers HGJM, Huisman AM, Dann O (1983) Diamidino yellow dihydrochloride (DY-2HCl); a new fluorescent retrograde neuronal tracer which migrates only very slowly out of the cell. Exp Brain Res 51:179-191.

Kendall HO, Kendall FP, Wadsworth GE (1971) Muscles: testing and function, 2d ed. Baltimore: Williams and Wilkins.

Kievit J, Kuypers HGJM (1977) Organization of the thalamo-cortical connexions to the frontal lobe in the rhesus monkey. Exp Brain Res 29:299-322.

Kubota K, Hamada I (1978) Visual tracking and neuron activity in the post-arcuate area in monkeys. J Physiol (Paris) 74:297-312.

Kurata K (1989) Distribution of neurons with set- and movementrelated activity before hand and foot movements in the premotor cortex of rhesus monkey. Exp Brain Res 77:245-256.

Kurata K (1991) Corticocortical inputs to the dorsal and ventral aspects of the premotor cortex of macaque monkeys. Neurosci Res 12: 263-280.

Kurata K, Tanji J (1986) Premotor cortex neurons in macaques: activity before distal and proximal forelimb movements. J Neurosci 6:403-411.

Kurata K, Wise SP (1988a) Premotor cortex of rhesus monkeys: setrelated activity during two conditional motor tasks. Exp Brain Res 69:327-343

Kurata K, Wise SP (1988b) Premotor and supplementary motor cortex in rhesus monkeys: neuronal activity during externally- and internally-instructed motor tasks. Exp Brain Res 72:237-248.

Kurata K, Okano K, Tanji J (1985) Distribution of neurons related to a hindlimb as opposed to forelimb movement in the monkey premotor cortex. Exp Brain Res 60:188-191.

Kuypers HGJM (1981) Anatomy of the descending pathways. In: Handbook of physiology, Sec I, The nervous system, Vol II, Motor control, Pt I (Brooks VB, ed), pp 567-666. Bethesda, MD: American Physiological Society.

Kuypers HGJM, Brinkman J (1970) Precentral projections to different parts of the spinal intermediate zone in the rhesus monkey. Brain Res 24:29-48.

Kuypers HGJM, Huisman AM (1984) Fluorescent neuronal tracers. Adv Cell Neurobiol 5:307-340.

Kwan HC, MacKay WA, Murphy JT, Wong YC (1978) Spatial organization of precentral cortex in awake primates. II. Motor outputs. J Neurophysiol 41:1120-1131. 
Liu CN, Chambers WW (1964) An experimental study of the corticospinal system in the monkey (Macaca mulatta). The spinal pathways and preterminal distribution of degenerating fibers following discrete lesion of the pre- and postcentral gyri and bulbar pyramid. J Comp Neurol 123:257-284.

Lu MT, Strick PL (1990) Prefrontal connections with the premotor areas. Soc Neurosci Abstr 16:241.

Luppino G, Matelli M, Camarda RM, Gallese V, Rizzolatti G (1991) Multiple representations of body movements in mesial area 6 and the adjacent cingulate cortex: an intracortical microstimulation study in the macaque monkey. J Comp Neurol 311:463-482.

Martino AM, Strick PL (1987) Corticospinal projections originate from the arcuate premotor area. Brain Res 404:307-312.

Matelli M, Luppino G, Rizzolatti G (1985) Patterns of cytochrome oxidase activity in the frontal agranular cortex of the macaque monkey. Behav Brain Res 18:125-136.

Matelli M, Camarda R, Glickstein M, Rizzolatti G (1986) Afferent and efferent projections of the inferior area 6 in the macaque monkey. J Comp Neurol 251:281-298.

Matelli M, Luppino G, Fogassi L, Rizzolatti G (1989) Thalamic input to inferior area 6 and area 4 in the macaque monkey. J Comp Neurol 280:468-488.

Matelli M, Luppino G, Rizzolatti G (1991) Architecture of superior and mesial area 6 and the adjacent cingulate cortex in the macaque monkey. J Comp Neurol 311:445-462.

Matsumura M, Kubota K (1979) Cortical projection to hand-arm motor area from post-arcuate area in macaque monkeys: a histological study of retrograde transport of horseradish peroxidase. Neurosci Lett $11: 241-246$

Mesulam MM (1982) Tracing neural connections with horseradish peroxidase. New York: Wiley.

Mitz AR, Wise SP (1987) The somatotopic organization of the supplementary motor area: intracortical microstimulation mapping. J Neurosci 7:1010-1021.

Muakkassa KF, Strick PL (1979) Frontal lobe inputs to primate motor cortex: evidence for four somatotopically organized 'premotor' areas. Brain Res 177:176-182.

Murray EA, Coulter JD (1981) Organization of corticospinal neurons in the monkey. J Comp Neurol 195:339-365.

Mushiake H, Inase M, Tanji J (1991) Neuronal activity in the primate premotor, supplementary and precentral motor cortex during visually guided and internally determined sequential movements. J Neurophysiol 66:705-716.

Pellegrino GD, Wise SP (1991) A neurophysiological comparison of three distinct regions of the primate frontal lobe. Brain 114:951-978.

Petrides M, Pandya DN (1984) Projections to the frontal cortex from the posterior parietal region in the rhesus monkey. J Comp Neurol 228:105-116.

Preuss TM, Goldman-Rakic PS (1989) Connections of the ventral granular frontal cortex of macaques with perisylvian premotor and somatosensory areas: anatomical evidence for somatic representation in primate frontal association cortex. J Comp Neurol 282:293-316.

Rapoport S (1978) Location of sternocleidomastoid and trapezius motoneurone in the cat. Brain Res 156:339-344.

Reed AF (1940) The nuclear masses in the cervical spinal cord of Macaca mulatta. J Comp Neurol 72:187-206.

Richmond FJR, Scott DA, Abrahams VC (1978) Distribution of motoneurones to the neck muscles, biventer cervices, splenius and complexus in the cat. J Comp Neurol 181:451-464.

Riehle A, Requin J (1989) Monkey primary motor and premotor cortex: single-cell activity related to prior information about direction and extent of an intended movement. J Neurophysiol 61:534-549.

Rizzolatti G, Scandolara C, Matelli M, Gentilucci M (1981a) Afferent properties of periarcuate neurons in macaque monkeys. I. Somatosensory responses. Behav Brain Res 2:125-146.

Rizzolatti G, Scandolara C, Matelli M, Gentilucci M (1981b) Afferent properties of periarcuate neurons in macaque monkeys. II. Visual responses. Behav Brain Res 2:147-163.

Rizzolatti G, Camarda R, Fogassi L, Gentilucci M, Luppino G, Matelli $M$ (1988) Functional organization of inferior area 6 in the macaque monkey. II. Area F5 and the control of distal movements. Exp Brain Res 71:491-507.

Rosene DL, Mesulam MM (1978) Fixation variables in horseradish pcroxidasc neurohistochemistry. I. The effects of fixation time and perfusion procedures upon enzyme activity. J Histochem Cytochem $26: 28-39$.
Rosene DL, Roy NJ, Davis BJ (1986) A cryoprotection method that facilitates cutting frozen sections of whole monkey brains for histological and histochemical processing without freezing artifact. J Histochem Cytochem 34:1301-1315.

Rosina A (1982) Rapid anterograde movement of the fluorescent tracer fast blue: a new method for tracing central connections. Neurosci Lett 33:217-221.

Sato KC, Tanji J (1989) Digit-muscle responses evoked from multiple intracortical foci in monkey precentral motor cortex. J Neurophysiol 62:959-970.

Schell GR, Strick PL (1984) The origin of thalamic inputs to the arcuate premotor and supplementary motor areas. J Neurosci 4:539_ 560.

Sessle BJ, Wiesendanger M (1982) Structural and functional definition of the motor cortex in the monkey (Macaca fascicularis). J Physiol (Lond) 323:245-265.

Sherrington CS (1898) Experiments in examination of the peripheral distribution of the fibers of the posterior roots of some spinal nerves. Philos Trans R Soc Lund [Biol] 190:45-186.

Shinoda Y, Zarzecki P, Asanuma H (1979) Spinal branching of pyramidal tract neurons in the monkey. Exp Drain Res 34:59-72.

Sprague JM (1948) A study of motor cell localization in the spinal cord of the rhesus monkey. Am J Anat 82:1-26.

Strick PL (1985) How do the basal ganglia and cerebellum gain access to the cortical motor areas? Behav Brain Res 18:107-123.

Strick PL (1988) Anatomical organization of multiple motor areas in the frontal lobe: implications for recovery of function. In: Advances in neurology, Vol 47, Functional recovery in neurological disease (Waxman SG, ed), pp 293-312. New York: Raven.

Tanji J, Kurata K (1982) Comparison of movement-related activity in two cortical motor areas of primates. J Neurophysiol 48:633-653.

Tanji J, Wise SP (1981) Submodality distribution in sensorimotor cortex of the unanesthetized monkey. J Neurophysiol 45:467-481.

Ueyama T, Satoda T, Tashiro T, Sugimoto T, Matsushima R, Mizuno $N$ (1990) Infrahyoid and accessory motoncuronc in the Japancsc monkey (Macaca fuscata). J Comp Neurol 291:373-382.

Vogt C, Vogt O (1919) Allgemeinere ergebnisse unserer hirnforschung. J Psychol Neurol (Leipzig) 25:277-462.

Waters RS, Samulack DD, Dykes RW, McKinley PA (1990) Topographic organization of baboon primary motor cortex: face, hand, forelimb, and shoulder representation. Somatosens Motor Res 7:485514.

Weidner C, Miceli D, Reperant J (1983) Orthograde axonal transport and transcellular transport of different fluorescent tracers in the primary visual system of the rat. Brain Res 272:129-136.

Weinrich M, Wise SP (1982) The premotor cortex of the monkey. J Neurosci 2:1329-1345.

Weinrich M, Wise SP, Mauritz KH (1984) A neurophysiological study of the premotor cortex in the rhesus monkey. Brain 107:385-414.

Wiesendanger M (1981) Organization of secondary motor areas of cerebral cortex. In: Handbook of physiology, Sec I, The nervous system, Vol II, Motor control, Pt 2 (Brooks VB, ed), pp 1121-1147. Bethesda, MD: American Physiological Society.

Wiesendanger M, Wiesendanger R (1984) The supplementary motor area in the light of recent investigations. Exp Brain Res [Suppl] 9:382392.

Wise SP (1985) The primate premotor cortex: past, present, and preparatory. Annu Rev Neurosci 8:1-19.

Wise SP, Mauritz KH (1985) Set-related neuronal activity in the premotor cortex of rhesus monkeys: effects of changes in motor set. Proc R Soc Lond [Biol] 223:331-354.

Wise SP, Tanji J (1981) Supplementary and precentral motor cortex: contrast in responsiveness to peripheral input in the hindlimb area of the unanesthetized monkey. J Comp Neurol 195:433-451.

Wise SP, Alexander GE, Altman JS, Brooks VB, Freund H-J, Fromm CJ, Humphrey DR, Sasaki K, Strick PL, Tanji J, Vogel S, Wiesendanger M (1991) Group report: what are the specific functions of the different motor areas? In: Motor control: concepts and issues (Humphrey DR, Freund H-J, eds), pp 463-485. London: Wiley.

Woolsey CN, Settlage PH, Meyer DR, Sencer W, Hamuy TP, Travis AM (1952) Patterns of localization in precentral and "supplementary" motor area and their relation to the concept of a premotor area. Assoc Res Nerv Ment Dis 30:238-264. 